\title{
Impact of Comorbidities on Myocardial Remodeling and Dysfunction In Heart Failure with Preserved Ejection Fraction
}

\author{
L. van Heerebeek ${ }^{1,2 *}$ and Walter J. Paulus ${ }^{2}$ \\ ${ }^{1}$ Institute for Cardiovascular Research VU (ICaR-VU), The Netherlands \\ ${ }^{2}$ VU University Medical Center Amsterdam, Amsterdam, The Netherlands
}

Received: June 03, 2014, Accepted: July 28, 2014, Published: August 20, 2014

*Corresponding author: Loek van Heerebeek, Department of Physiology, Institute for Cardiovascular Research VU (ICaR-VU), VU University Medical Center Amsterdam, Van der Boechorststraat 7, 1081 BT Amsterdam, The Netherlands, Tel: 31-20-4448110; Fax: 31-20-4448255; E-mail: l.vanheerebeek@vumc.nl

\begin{abstract}
Heart failure (HF) with preserved ejection (HFpEF) is widely prevalent and associated with poor outcome and incompletely understood pathophysiology. In contrast to HF with reduced $\mathrm{EF}$ (HFrEF), modern HF pharmacotherapy did not improve outcome in HFpEF, which emphasizes the urgent need to elucidate responsible pathogenetic mechanisms in HFpEF. Over the last decennium, myocardial structure, cardiomyocyte function and intramyocardial signaling were shown to be specifically altered in HFpEF. Myocardial remodelling and dysfunction in HFpEF comprises myocardial hypertrophy and fibrosis and increased cardiomyocyte stiffness. Increased cardiomyocyte stiffness in HFpEF importantly contributes to high left ventricular (LV) diastolic stiffness and results from specific changes in transcriptional and posttranslational modifications of the giant elastic sarcomeric protein, titin. Increased systemic vascular inflammation, endothelial dysfunction and oxidative stress resulting in reduced nitric oxide (NO) bioavailability appear importantly involved in increased diastolic LV stiffness and adverse remodelling in HFpEF. Recently, a new paradigm for HFpEF was proposed, which suggests that prevalent comorbidities, such as overweight/obesity, diabetes, hypertension, chronic pulmonary obstructive disease, anemia and chronic kidney dysfunction drive myocardial dysfunction and remodelling through coronary microvascular endothelial inflammation. Additional demographic characteristics in HFpEF are older age and female predominance, which could contribute to maladaptive cardiovascular structural and functional changes in a synergistic manner with the prevalent comorbidities. Although HFpEF is associated with more impaired cardiovascular abnormalities and worse outcome beyond the level explainable by comorbidities alone, the rationale for an important involvement of noncardiac comorbidities in myocardial dysfunction and remodeling in $\mathrm{HFpEF}$ seems plausible. In the following review, this rationale of an important involvement of comorbidities in HFpEF pathophysiology is further addressed in light of the proposed new HFpEF paradigm.
\end{abstract}

Keywords: Heart failure; Endothelial dysfunction; Comorbidities; Nitric oxide; Oxidative stress

\section{Introduction}

Heart failure with preserved ejection fraction (HFpEF) currently accounts for $50 \%$ of all HF patients, and its prevalence relative to $\mathrm{HF}$ with reduced $\mathrm{EF}$ ( $\mathrm{HFrEF}$ ) is rising at a rate of approximately $1 \%$ per year $[1,2]$. Patients with HFpEF have a poor prognosis, with only slight lower mortality rates than patients with HFrEF $[1,3]$. According to current critera, HFpEF is diagnosed in the presence of signs and/or symptoms of HF, preserved systolic left ventricular (LV) function, with a LV ejection fraction (LVEF) $>50 \%$ and $L V$ end-diastolic volume index (LVEDVI) $<97 \mathrm{ml} / \mathrm{m}^{2}$ and evidence of diastolic $\mathrm{LV}$ dysfunction [4]. Conversely, $\mathrm{HFrEF}$ is diagnosed in the presence of HF signs and/or symptoms and reduced LVEF [4]. In contrast to HFrEF, modern HF pharmacotherapy did not improve outcome in $\mathrm{HFpEF}$, which is attributed to the incomplete understanding of HFpEF pathophysiology $[5,6]$. Furthermore, diastolic LV dysfunction is not the sole abnormality in HFpEF and other mechanisms were also found to contribute, such as systolic LV dysfunction [79], ventricular-vascular stiffening [10-13], impaired systemic vasodilatory reserve [13-15], chronotropic incompetence [1214], and pulmonary hypertension [16,17]. HFpEF patients are generally older, more often female and have high prevalence of noncardiac comorbidities, such as overweight/obesity, hypertension, diabetes (DM), chronic obstructive pulmonary disease (COPD), anemia and chronic kidney disease [18-21]. Systemic inflammation and endothelial dysfunction are important hallmarks of these comorbidities. Recently, a new paradigm of HFpEF was suggested, which proposes that comorbidities drive myocardial dysfunction and remodelling in $\mathrm{HFpEF}$ through coronary microvascular endothelial inflammation [22]. This review will discuss the relevance of comorbidities for HFpEF in light of this new paradigm.

\section{Myocardial Remodeling and Dysfunction in HFpEF}

Diastolic dysfunction in HFpEF represents the dominant 
abnormality and is evident from slow LV relaxation and elevated diastolic LV stiffness, which increase diastolic filling pressures and limit cardiac performance at rest, during atrial pacing and exercise $[15,23,24]$. Baseline characteristics of HFpEF patients in the Treatment of Preserved Cardiac Function Heart Failure With an Aldosterone Antagonist (TOPCAT) [25] and Irbesartan in Heart Failure with Preserved Ejection Fraction (I-preserve) [26] trials demonstrate structural cardiac remodeling in many HFpEF patients including concentric LV remodeling and hypertrophy (59-77\%) and left atrial (LA) dilatation (59$66 \%)$. At the microscopic level, HFpEF patients had increased cardiomyocyte diameter and extracellular matrix (ECM) changes [27]. In HFpEF, both qualitative and quantitative ECM changes contribute to increased myocardial diastolic stiffness, such as increased deposition of interstitial collagen, higher expression of collagen type 1 and collagen crosslinking [28-30]. In addition to myocardial fibrosis, increased cardiomyocyte stiffness also importantly contributes to high diastolic LV stiffness in HFpEF $[27,31,32]$. Cardiomyocyte stiffness is mainly determined by the elastic sarcomeric protein titin, which functions as a bidirectional spring, responsible for early diastolic recoil and late diastolic distensibility [32]. Titin-based cardiomyocyte stiffness results from dynamic changes in expression of stiff (N2B) and compliant (N2BA) isoforms and from isoform phosphorylation status [32]. Phosphorylation of titin by protein kinase A (PKA) [33] and PKG [34] increase its compliance (Figure 1), in contrast to PKC [35], which makes it less compliant. Various studies, which procured endomyocardial tissue from HFpEF, HFrEF and aortic stenosis (AS) patients demonstrated significantly stiffer cardiomyocytes in HFpEF than in HFrEF and AS patients [36,37]. This increased cardiomyocyte stiffness was related to increased expression of the stiff titin N2B isoform relative to HFrEF, and to reduced phosphorylation of titin. Hypophosphorylation of titin resulted from lower myocardial PKG activity and reduced myocardial cyclic guanosine monophosphate (cGMP) concentration in HFpEF compared to HFrEF and AS [37] (Figure 2A). Myocardial PKG plays a pivotal role in normal cardiovascular physiology and PKG phosphorylates a vast number of target proteins, exerting a wide range of downstream effects, such as inhibition of the L-type calcium channel, enhancement of intracellular diastolic calcium reuptake through phosphorylation of phospholamban (PLB), suppression of hypertrophic signaling through inhibition of G-protein coupled receptors and the transient receptor potential canonical channel, inhibition of ischemia-reperfusion injury through phosphorylation of the ATP-sensitive potassium channel and stimulation of LV relaxation and distensibility by phosphorylation of troponin I (TnI) and titin(Figure1) [38]. Myocardial cGMP-PKG signaling is coupled upstream to stimulation by two distinct pathways including the natriuretic peptide (NP)-particulate guanylate cyclase (pGC) pathway and the nitric oxide (NO)-soluble GC (sGC) pathway [38] (Figure 1). Although myocardial brain-type natriuretic peptide (BNP) expression is lower in HFpEF than in HFrEF, the significantly reduced myocardial cGMP-PKG activity in HFpEF, compared to HFrEF and AS could not be explained by lower myocardial BNP expression alone [37]. Because myocardial nitrotyrosine expression, which is an indirect marker of nitrosative/oxidative stress, was 4 times higher in HFpEF than in HFrEF and AS, reduced myocardial NO bioavailability was suggested to underlie the downregulation of myocardial cGMP-PKG signaling in HFpEF [37](Figure 2B). Increased nitrosative/oxidative stress in HFpEF was inferred from the higher prevalence in HFpEF of comorbidities as hypertension, obesity and DM, which are known to elicit inflammatory responses. Recent findings indeed demonstrate an important role for endothelial dysfunction $[13,14,39]$ and inflammation [40] in HFpEF pathophysiology.

\section{Endothelial Dysfunction}

The vascular endothelium produces and secretes numerous compounds that regulate a variety of physiological functions, including vasomotor tone, coagulation, inflammation, permeability and cell adhesion [41]. NO is considered the key molecule in maintaining adequate vasodilatory function. Endothelial dysfunction is characterized by impaired vasomotor response, cell proliferation, platelet adhesion/aggregation, vascular permeability and leucocyte-endothelial interactions that participate in vascular inflammation [42]. Recent studies demonstrated a high prevalence of endothelial dysfunction in HFpEF patients, which was related to reduced exercise capacity [13] and worse outcome [39]. This prognostic implication suggests a causal involvement of endothelial dysfunction in HFpEF [43]. Endothelial dysfunction in HFpEF is also evident from reduced aortic distensibility [44], higher arterial load [45] and deficient vasodilatory reserve $[13,14]$, which contribute to reduced exercise tolerance. Probably because of upregulation of endothelial nitric oxide synthase, this response was reversed following an exercise training programme [46], which improved both exercise capacity and diastolic LV dysfunction [47].

\section{Inflammation}

Myocardial inflammation was shown to contribute to ECM changes and diastolic dysfunction in HFpEF [40]. In an endomyocardial biopsy study, when compared with controls, HFpEF patients had increased inflammatory cell transforming growth factor (TGF- $\beta$ ) expression, which induces transdifferentiation of fibroblasts into myofibroblasts, with increased production of collagen and decreased expression of matrix metalloproteinase type 1 (MMP1), whereas both myocardial collagen and the amount of inflammatory cells correlated with diastolic LV dysfunction [40]. As compared with asymptomatic hypertensives, HFpEF patients had increased circulating biomarkers of inflammation (interleukin 6 (IL6), IL8, monocyte chemoattractant protein 1 (MCP1), of collagen metabolism (aminoterminal propeptide of collagen III, carboxyterminal telopeptide of collagen I), and of ECM turnover (MMP2 and MMP9) [48]. In addition, MMP9, tissue inhibitor of matrix metalloproteinases type 1 (TIMP1), and the ratio of MMP9/TIMP1 correctly identified patients with a high left atrial volume index, which reflects chronic diastolic LV dysfunction [48]. Moreover, the Health $\mathrm{ABC}$ study reported inflammatory biomarkers such as IL6 and tumor necrosis factor $\alpha$ (TNF- $\alpha$ ) to be strongly associated with incident HFpEF, but not incident HFrEF in elderly patients [49]. Serum IL16 levels were specifically elevated in HFpEF 


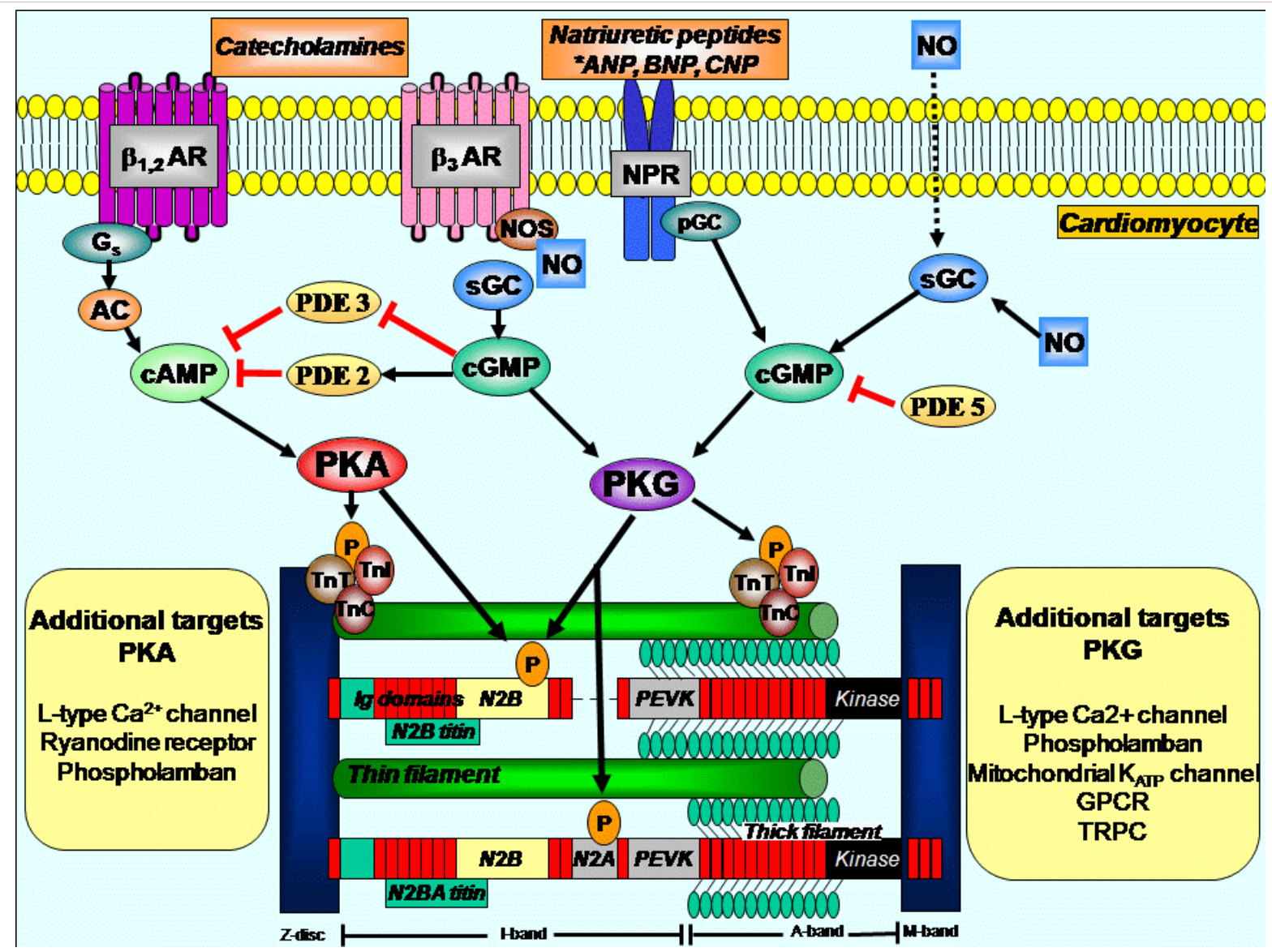

Figure 1: Cardiomyocyte cAMP and cGMP signalling pathways involved in regulating cardiac contractility, lusitropy and titin-based stiffness.

Stimulation of $\beta_{1,2}$-ARs activates $G_{s}$-AC-mediated generation of cAMP, which stimulates PKA activity. PKA induces inotropic, chronotropic and lusitropic effects through phosphorylation of L-type calcium channels, ryanodine receptors, phospholamban, TnI; while it lowers titin-based cardiomyocyte stiffness through phosphorylation of the N2B segment of titin. Generation of cGMP results from either activation of sGC by NO or from activation of pGC by NPs. Activation of PKG results from stimulation by the second messenger cGMP. PKG induces negative inotropic effects and stimulates relaxation and lowers titin-based cardiomyocyte stiffness through phosphorylation of the N2B segment of titin. cGMP-PKG signaling is offset by PDE5-mediated hydrolysis of cGMP. Stimulation of the $\beta_{3}$-AR mediates negative inotropic effects through stimulation of NOS-NO-cGMP signaling. Substantial crosstalk exists between cGMP and cAMP signaling cascades. With concomitant $\beta$-adrenergic activity, cGMP inhibits cAMP through stimulation of PDE2-mediated cAMP hydrolysis. cGMP can also enhance cAMP through inhibition of PDE3-mediated cAMP hydrolysis. Circled

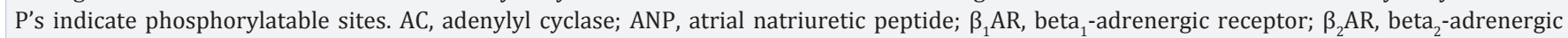
receptor; $\beta_{3} \mathrm{AR}$, beta ${ }_{3}$-adrenergic receptor; $\mathrm{BNP}$, brain type natriuretic peptide; cAMP, cyclic adenosine monophosphate; cGMP, cyclic guanosine monophosphate; CNP, C-type natriuretic peptide; G, G-stimulatory protein; GPCR, G protein coupled receptor; TRPC, transient receptor potential canonical channel; PDE5, phosphodiesterase type 5; Ig's, immunoglobulin domains; NO, nitric oxide; NOS, nitric oxide synthase; NPR, natriuretic peptide receptor; PEVK, unique sequence rich in proline, glutamic acid, valine and lysine; PDE2, phosphodiesterase type 2; PDE3, phosphodiesterase type 3; PDE5, phosphodiesterase type 5; pGC, partriculate guanylate cyclase; sGC, soluble guanylate cyclase; TnC, troponin C; TnI, troponin I; TnT, troponin $\mathrm{T}$.

patients compared to HFrEF and controls and associated with diastolic LV dysfunction [50]. Enhanced cardiac expression of IL16 in transgenic mice induced cardiac fibrosis and LV myocardial stiffening accompanied by increased macrophage infiltration [50]. Recently, galectin-3, a $\beta$-galactoside-binding member of the lectin family, was found to reflect inflammatory and fibrotic processes and predicted all-cause mortality and HF hospitalizations [51] especially in HFpEF patients [52].

\section{New Paradigm of HFpEF}

In the new paradigm of HFpEF, comorbidities were proposed to contribute to high diastolic LV stiffness through induction of systemic inflammation and oxidative stress, which elicits coronary microvascular endothelial dysfunction and downregulation of myocardial NO-cGMP-PKG signaling (Figure 3). This chain of events results in increased cardiomyocyte stiffness through hypophosphorylation of titin, cardiomyocyte hypertrophy and enhanced myocardial interstitial fibrosis [22]. Prevalent noncardiac comorbidities in HFpEF share systemic inflammation and oxidative stress as a common feature and could therefore be implicated in myocardial dysfunction and remodeling in HFpEF. Therefore, an indepth overview of clinical and pathological 


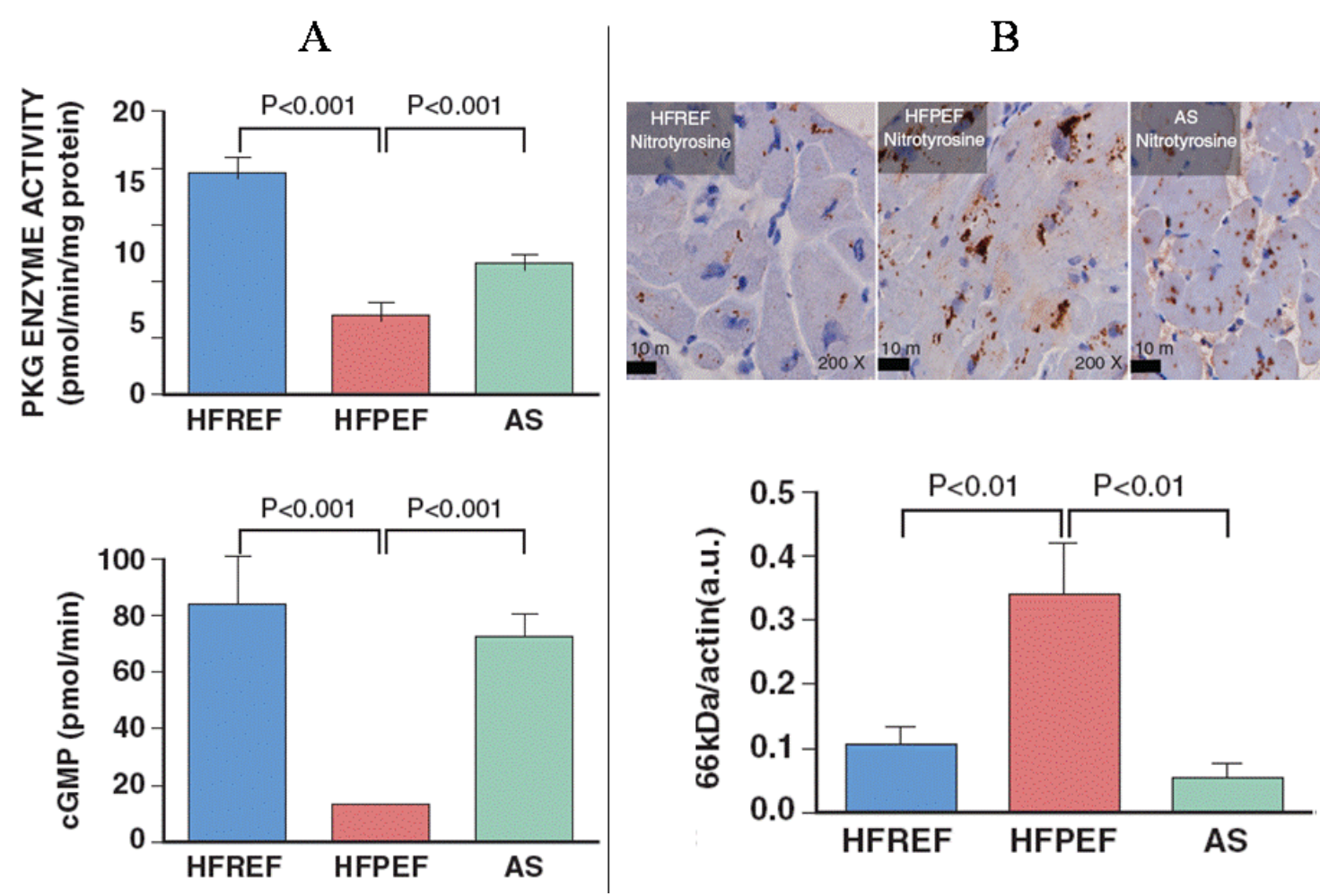

Figure 2: Myocardial PKG activity, cGMP concentration and nitrotyrosine expression.

A: Lower myocardial PKG activity in HFpPEF (DHF) than in HFrEF (SHF) and aortic stenosis (AS) patients. B: Higher myocardial nitrotyrosine levels, indicative of nitrosative/oxidative stress in HFpEF (DHF) than in HFrEF (SHF) or AS. Reproduced with permission from van Heerebeek L et al. Circulation 2012; 126:830-839.

characteristics of noncardiac comorbidities relevant for HFpEF pathophysiology will be provided in the next paragraphs.

\section{Comorbidities in HFpEF}

Noncardiac comorbidities are highly prevalent in $\mathrm{HFpEF}$ [21], which increase hospitalization risk, with more non-HF admissions compared with HFrEF [21]. The most important are overweight/obesity, hypertension, DM, COPD, anemia and chronic kidney disease. However, HFpEF does not simply represent a collection of comorbidities as HFpEF patients exhibit a worse outcome compared with patients with various comorbidities [53]. Mortality rates were much higher in HFpEF patients (53 to 76 per 1,000 patient-years) than in non-HFpEF patients with similar age, sex and comorbidity distribution (11 to 47 per 1,000 patient-years) [53]. A comparative analysis of HFpEF patients, age- and sex-matched health controls and hypertensive controls demonstrated more cardiovascular abnormalities in HFpEF patients than in the other groups, even after accounting for age, sex, body size and comorbidities [54]. These findings support additional deterioration in HFpEF by HF-related mechanisms such as neuroendocrine activation [55] and lack of high energy phosphates [12]. Nevertheless, noncardiac comorbidities can adversely affect myocardial function and remodeling and likely play a role in HFpEF pathophysiology.

\section{Increased age}

Half of all HF diagnoses and $90 \%$ of all HF deaths occur in patients aged above 70 years while HF incidence doubles with each decade of life [56]. Ageing is associated with various abnormalities in cardiovascular structure and function [57]. The prevalence of LV hypertrophy and HF increases dramatically with age [58]. Increased LV wall thickness has been attributed to increased myocardial collagen deposition and cardiomyocyte size [59]. At the subcellular level, ageing is accompanied by disturbed diastolic calcium handling, $\beta$-adrenergic signaling and mitochondrial dysfunction, which impair diastolic function causing progressive slowing of early LV diastolic filling rate, whereas LVEF is preserved [60]. Despite LVEDVI being unchanged or even greater at exercise, there is an age-associated deficit in the ability to reduce LV end-systolic volume index, which compromises LV stroke volume reserve with exercise [57]. Maximum cardiac output reserve also decreases with ageing due to chronotropic incompetence with a reduction in peak heart rate of $30 \%$ between 20 and 85 years of age [61]. The inability to enhance contractility and heart rate response with exercise have been allocated to disturbed autonomic control and diminished efficiency of post-synaptic $\beta$-adrenergic signaling [62]. Furthermore, ageing is associated with arterial stiffening, widening of pulse pressure and endothelial dysfunction, which are risk factors for future cardiovascular events [60]. Increased arterial stiffness is governed by structural changes in the vascular wall, such as calcification, increased collagen content and reduced elastin and by endothelial regulation of vascular 


\section{MYOCARDIAL REMODELING IN HFPEF Importance of Comorbidities}

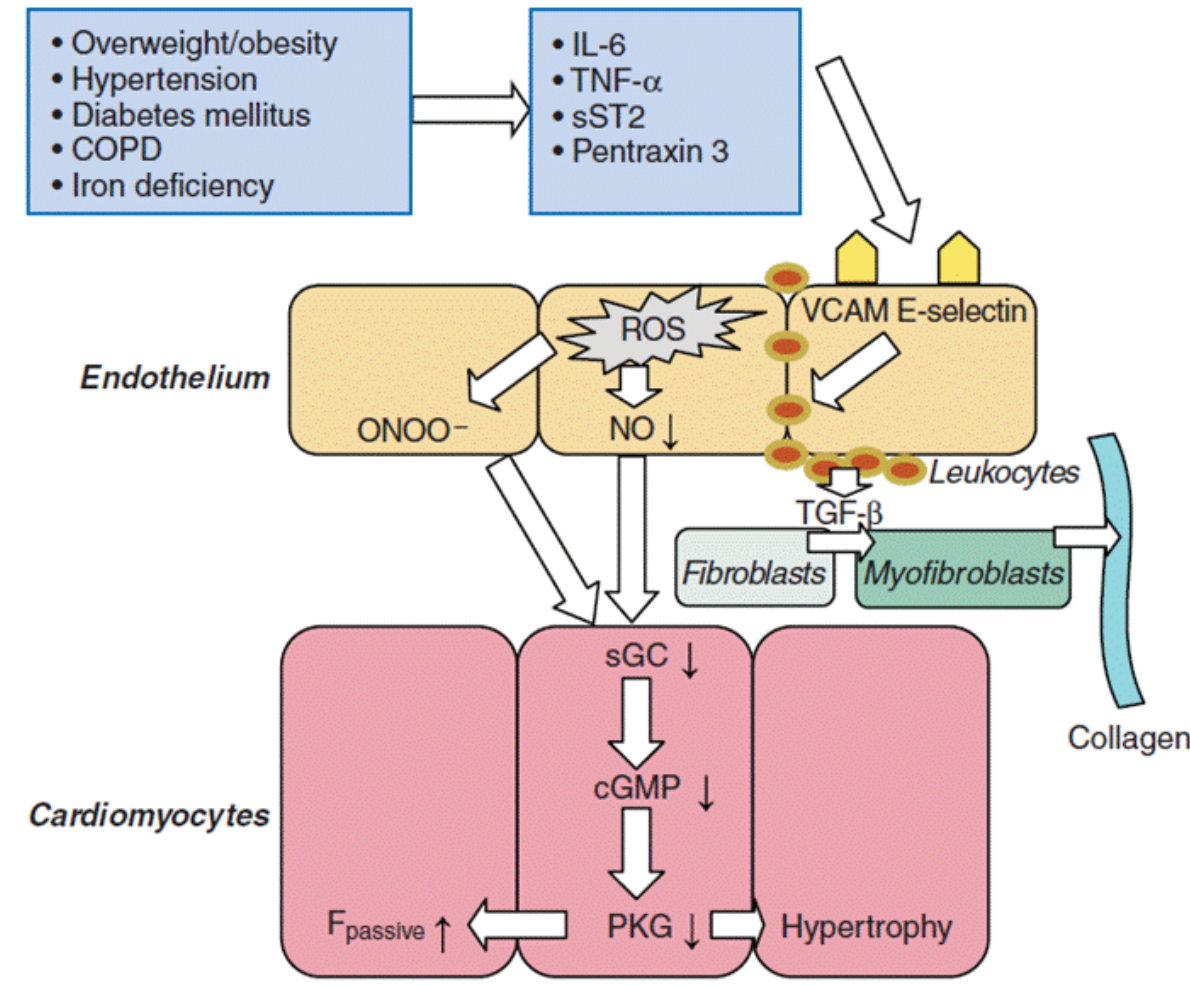

Figure 3: Comorbidities drive myocardial dysfunction and remodeling in HFPEF.

Comorbidities induce a systemic proinflammatory state with elevated plasma levels of in IL-6, TNF- $\alpha$, sST2 and pentraxin 3. Coronary microvascular endothelial cells reactively produce ROS, VCAM and E-selectin. Production of ROS leads to formation of peroxynitrite (ONOO-) and reduced NO bioavailability, both of which lower sGC activity in adjacent cardiomyocytes. Lower sGC activity decreases cGMP concentration and PKG activity. Low PKG activity raises resting tension $\left(\mathrm{F}_{\text {passive }}\right.$ ) of cardiomyocytes because of hypophosphorylation of titin and removes the brake on prohypertrophic stimuli inducing cardiomyocyte hypertrophy. VCAM and E-selectin expression in endothelial cells favours migration into the subendothelium of monocytes. These monocytes release TGF- $\beta$. The latter stimulates conversion of fibroblasts to myofibroblasts, which deposit collagen in the interstitial space. Modified with permission from Paulus WJ et al. J Am Coll Cardiol 2013;62:263-271.

smooth muscle tone [63]. Arterial stiffness also explains isolated systolic hypertension and widening of pulse pressure, which are frequently encountered in the elderly, being associated with increased risk of cardiovascular events [64]. Combined ventricular-vascular stiffening causes labile blood pressure swings with relatively minor changes in pre- and afterload [11]. Endothelial dysfunction importantly contributes to vascular stiffening and age-associated enhanced endothelial expression of adhesion molecules and inflammatory mediators impair NObioavailability [57]. Increased oxidative stress and activation of the renin-angiotensin-aldosterone system (RAAS) play an important role in age-related arterial stiffening and endothelial dysfunction [57]. Conversely, physical exercise, which improves endothelial dysfunction, was found to preserve LV compliance in elderly athletes compared to sedentary seniors [65]. As a result of coronary microvascular endothelial inflammation, the vasodilator response of the coronary microvascular bed to acetylcholine was reduced in HFpEF, which correlated with diastolic LV dysfunction [66]. Similar paracrine endocardialmyocardial interactions have previously already been reported [67].

\section{Female gender}

HFpEF patients are more likely to be female $[1,2,18-20]$, whereas female HFpEF patients tend to have a better outcome than male HFpEF patients [68]. In the I-PRESERVE trial, women with HFpEF were older and had higher prevalence of obesity, hypertension and chronic kidney disease and lower prevalence of ischemic heart disease compared to men [68]. Obesity and DM carry a greater risk in women and inhibit or impair myocardial metabolism more severely than in men $[69,70]$. Gender differences also exist for cardiovascular structural and functional remodeling as women more frequently have concentric remodeling, smaller LV diastolic chamber volumes, higher EF and increased systolic and diastolic LV stiffness [71]. Furthermore, women have higher pulsatile arterial loading and increased age-dependent vascular 


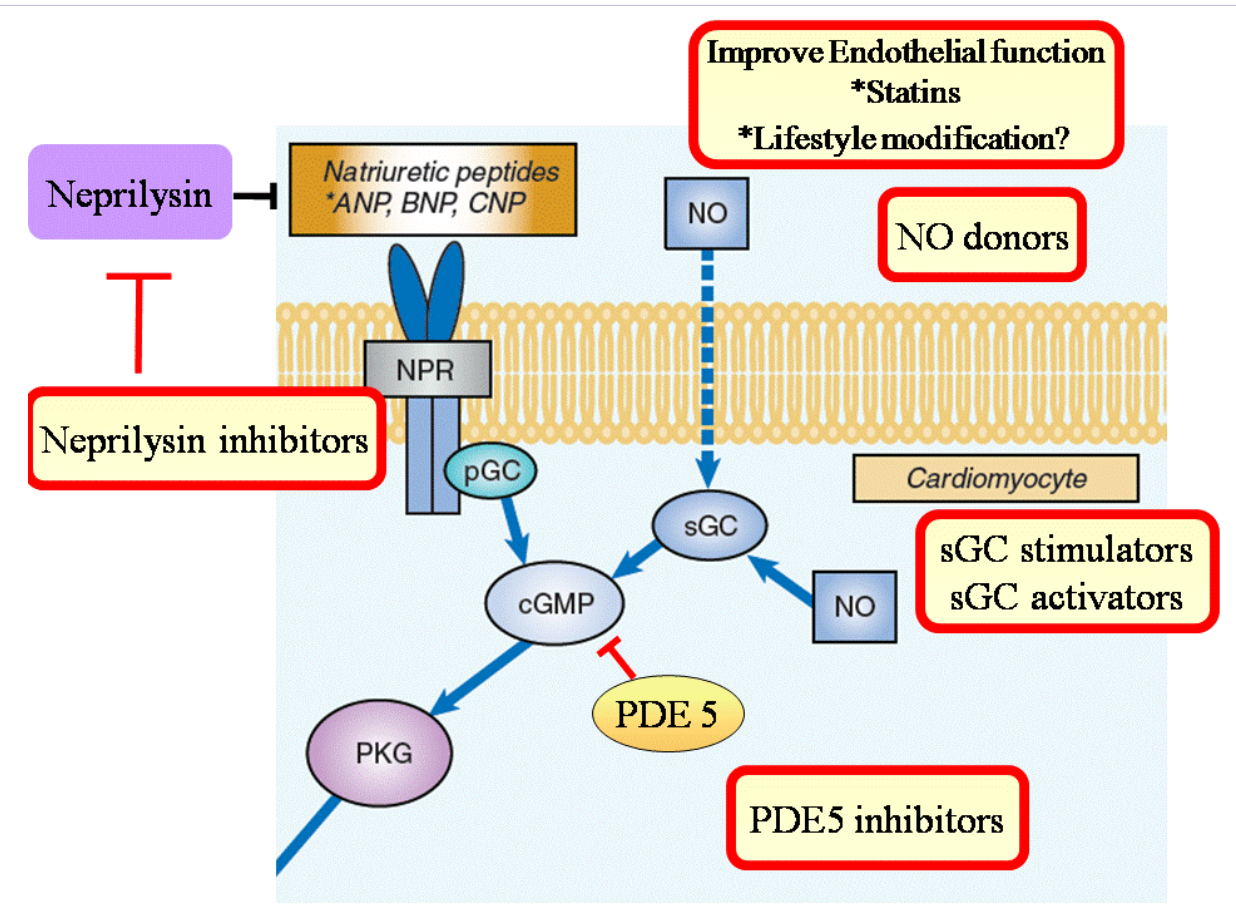

Figure 4: Therapeutic strategies to upregulate myocardial cGMP-PKG signaling.

NO, nitric oxide; sGC, soluble guanylate cyclase; NEP, neutral endopeptidase; pGC, particular guanylate cyclase; PKG, protein kinase G; PDE5, phosphodiesterase-5; cGMP, cyclic guanylate monophosphate.

stiffening compared to men [71]. The impact of ageing and of gender difference was nicely demonstrated in a longitudinal community based study, which compared systolic and diastolic ventricular stiffness and arterial stiffness at baseline and after 4 years follow up. Despite effective treatment of hypertension, regression of LV mass and reduction in arterial load, LV systolic and diastolic stiffness increased over 4 years in patients with and without cardiovascular disease, which were most pronounced in women [72]. Estrogens exert several cardiovascular protective effects, including inhibition of RAAS activation and myocardial fibrosis, stimulation of NO bioavailability and mitochondrial biogenesis and regulation of cardiomyocyte calcium handling [73]. The underlying mechanisms for maladaptive cardiovascular structural and functional remodeling in elderly women are incompletely understood, but declining estrogen levels or reduced sensitivity of estrogen-based signaling could be involved.

\section{COPD, Anemia and Renal failure}

Reduced forced expiratory volume in one second in COPD independently predicts incident $\mathrm{HF}$, which was attributed to the low grade systemic inflammation present in COPD [74]. COPD is both a premorbid identifier of HFpEF [75] and a contributor to HFpEF mortality [21]. In a population-based study, greater severity of COPD was linearly related to impaired LV filling, reduced stroke volume and lower cardiac output without changes in EF [76]. Anemia is more prevalent in HFpEF than in HFrEF patients [77] and associated with increased risk of HF hospitalization [78] and overall mortality [79]. Inflammation importantly contributes to anemia in HF [80], through impaired production of erythropoietin and causing bone marrow dysfunction [81]. The presence of anemia is frequently accompanied by iron deficiency [82]. In HF with or without anemia, iron deficiency contributes to immune responses and oxidative stress [83]. Chronic kidney disease is present in approximately $30-40 \%$ of $\mathrm{HF}$ patients and is an important predictor of mortality [84]. HF and chronic renal failure frequently co-exist, which can be related to common risk factors, such as hypertension, diabetes and atherosclerosis, but also to common pathogenic mechanisms such as neurohumoral activation, inflammation and oxidative stress [85].

\section{Hypertension}

The prevalence of arterial hypertension in HFpEF patients amounts approximately $60-88 \%$ [1,86-89]. The risk of developing $\mathrm{HF}$ after adjusting for age and other risk factors is approximately 2 -fold higher in hypertensive men and 3-fold higher in hypertensive women than in normotensive persons [90]. In a population-based European sample ( $\mathrm{n}=1274)$, arterial hypertension was shown to be an independent predictor of diastolic abnormalities [91]. Adverse cardiovascular effects of hypertension include LV hypertrophy, myocardial fibrosis and elevated arterial stiffness. Elevated arterial stiffness increases myocardial afterload, which results in impaired LV relaxation and increased LV filling pressures and oxygen consumption [92]. In hypertensive patients, markers of fibrosis related to asymptomatic diastolic dysfunction [93] and myocardial collagen turnover was greater in patients with more severe diastolic dysfunction [28]. Angiotensin II (AngII) has been shown to induce MCP1 expression in macrophages and upregulate TGF- $\beta$ in cardiomyocytes and fi- 
broblasts in animal models of pressure overload, suggesting that activation of the RAAS could precede the onset of inflammation and fibrosis in hypertensive HF [94]. Although arterial hypertension is usually perceived to induce HFpEF through myocardial afterload excess and LV hypertrophy [95], this paradigm was recently questioned [22]. In the Valsartan in Diastolic Dysfunction (VALIDD) trial only $3 \%$ of hypertensives had significant LV hypertrophy despite all having diastolic LV dysfunction [96]. In all HFpEF registries and large outcome trials $[2,18,89]$, arterial hypertension in HFpEF consists of elevated systolic pressure $( \pm 148$ $\mathrm{mmHg}$ ) but normal diastolic pressure $( \pm 83 \mathrm{mmHg})$. In HFpEF, LV cavity dimensions are small and especially in the presence of LV hypertrophy, the LV operates at a favorable Laplace relationship. LV systolic wall stress therefore remains low, despite elevated LV systolic pressure [97]. Conversely, inflammation, oxidative stress and endothelial dysfunction are importantly involved in hypertension $[98,99]$. Endothelial dysfunction in hypertensive patients was associated with increased plasma levels of TNF- $\alpha$, IL6, intercellular adhesion molecule 1 (ICAM-1), vascular cell adhesion molecule 1 (VCAM-1), E-selectin, C-reactive protein (CRP) and the von Willebrand factor, which is a marker of endothelial activation [99]. Markers of inflammation (urinary albumin, CRP, TNF- $\alpha$, and TGF- $\beta$ were independently associated with asymptomatic diastolic dysfunction [100]. High circulating IL6, TNF- $\alpha$, IL8 and MCP1 were detected in a cross-sectional study of 275 stable hypertensive patients with or without HFpEF [48]. In salt sensitive hypertension, high salt intake leads to systemic oxidative stress [101] possibly because of renal production of proinflammatory cytokines [102]. The RAAS is a major activator of NADPH oxidase and reactive oxygen species (ROS) production and increasing evidence reveals that the RAAS is importantly involved in linking obesity, metabolic syndrome, insulin resistance (IR), chronic kidney disease and hypertension [103]. Elevations in AngII and aldosterone have been shown to impair systemic insulin metabolic signaling that leads to endothelial dysfunction and myocardial functional abnormalities [103,104]. Some population studies and outcome trials observed a larger contribution to HFpEF development of metabolic comorbidities than of arterial hypertension. Hypertensive patients exhibit more frequent impairments of insulin metabolic signaling, dyslipidemia, micoralbuminuria and obesity [105]. In the MONICA registry, LA enlargement was strongly related to obesity, mildly related to age and unrelated to arterial hypertension [106].

\section{Metabolic risk factors}

HFpEF patients demonstrate a high prevalence of obesity and DM type II (DMII) [18-21,89]. Obesity and DMII are strongly related to IR and the metabolic syndrome (a constellation of cardiovascular risk factors, including obesity, hypertension, IR, hyperglycemia, dyslipidemia, microalbuminuria and hypercoagulability) $[107,108]$. The prevalence of obesity, IR, DMII and metabolic syndrome increases rapidly and is expected to reach pandemic proportions in the next few decades [107], while these metabolic risk factors have all been prospectively identified as precursors of incident HF [69,109-111] and are independently associated with early development of diastolic LV dysfunction [112-115]. The frequent clustering of these metabolic risk factors causes synergistic adverse effects on myocardial structure and function [107,108]. Furthermore, obesity, DMII and IR can have direct adverse effects on myocardial structure and function independently of common confounders as hypertension or coronary artery disease, which has been referred to as "obesity" [116], "diabetic" [117] or "insulin-resistant" [118] cardiomyopathy. Adverse myocardial structural and functional changes induced by obesity, DMII and IR include myocardial hypertrophy and fibrosis [119-121], reduced myocardial energetic reserve [122-124], impaired myocardial relaxation [115,125] and increased diastolic LV [72] and cardiomyocyte stiffness [126]. Metabolic risk factors are strongly associated with myocardial and systemic inflammation, oxidative stress and endothelial dysfunction [116-118], which importantly contribute to myocardial dysfunction and remodeling and result in downregulation of NO-cGMP-PKG signaling $[127,128]$.

\section{Overweight/Obesity}

Obesity is becoming a global epidemic and currently $70 \%$ of US adults are overweight or obese [129]. Obesity, defined as a body mass index (BMI) $\geq 30 \mathrm{~kg} / \mathrm{m}^{2}$ and overweight (BMI: 25.0 $29.9 \mathrm{~kg} / \mathrm{m}^{2}$ ) are independent risk factors for cardiovascular morbidity and mortality [130] and obesity doubles the risk of HF $[69,131]$ and DMII [132]. For each one unit increment in BMI, the risk of $\mathrm{HF}$ is increased by $7 \%$ in women and $5 \%$ in men [69]. In HFpEF, obesity also contributes to mortality as evident from the U-shaped relation between BMI and mortality [133]. Obesity induces maladaptive cardiac structural and functional changes. In a large population-based study, cardiac magnetic resonance imaging demonstrated that obesity was associated with concentric LV remodeling, increased LV mass/volume ratio, preserved LVEF [121,134] and LA dilatation [106]. Overweight and obesity are also associated with diastolic LV dysfunction independent of LV mass and associated risk factors [115]. Impaired myocardial relaxation results from obesity-induced myocardial mitochondrial dysfunction, lipotoxicity, uncoupled oxidative phosphorylation and disturbed cardiomyocyte calcium handling [135]. Compared to normal weight subjects, obese individuals had impaired myocardial energetics (phosphocreatine/ATP ratio) and diastolic filling rate at rest, which further deteriorated after inotropic stress [123]. Myocardial blood flow, as measured by PET, was significantly reduced in obese postmenopausal women, which was negatively correlated with waist/hip ratio [136]. Furthermore, in a comparative study including lean, overweight and obese subjects, although similar at rest, myocardial blood flow was significantly reduced in obese patients after cold pressor test - or dipyridamole-induced vasodilation [137]. Endothelial dysfuntion in obesity is prevalent and caused by activation of pro-inflammatory cytokines and increased oxidative stress [137-139]. In a rodent experimental model of obesity and IR, NO bioavailability was reduced resulting in a downregulation of cGMP-PKG signaling in vascular smooth muscle cells [140]. Increased lipid deposition in adipocytes leads to the production of proinflammatory cytokines and adipokines including TNF- $\alpha$, IL6, leptin and resistin, ultimately resulting in recruitment of monocytes and stimulation of monocyte differentiation into macrophages [138,141]. Adiponectin is the most abundant adipokine secreted by adipo- 
cytes and couples the regulation of insulin sensitivity with energy metabolism [142]. Decreased plasma adiponectin levels are observed in patients with obesity, DMII, hypertension and metabolic syndrome and are significantly associated with low-level chronic inflammatory conditions [143]. Adiponectin also stimulates endothelial NO production [144] and has anti-inflammatory properties [145]. Approximately $30 \%$ of obese individuals are free from IR and do not manifest the panoply of cardiovascular diseases usually observed in the obese [146]. The distribution pattern of fat deposition seems crucial in this regard with visceral fat being more pathogenic than subcutaneous fat. Abdominal rather than subcutaneous, fat releases pro-inflammatory cytokines and adipokines, causing low-grade systemic inflammation, increased circulating endothelial adhesion molecules and endothelial dysfunction [147]. In subjects with normal BMI, abdominal fat distribution was associated with impaired systolic and diastolic function, increased myocardial fibrosis markers, impaired insulin sensitivity and proinflammatory activation [148]. Excess visceral fat and IR, but not general adiposity, were independently associated with incident prediabetes and DMII in obese adults $[108,148]$. Moreover, in mesenteric arteries of morbidly obese individuals, endothelial dysfunction was only observed in the presence of IR, which related to augmented mitochondrial superoxide production and increased systemic inflammation mediated by TNF- $\alpha$ [149]. In addition to its association with systemic vascular inflammation and endothelial dysfunction, IR results in compensatory hyperinsulinemia, which induces LV hypertrophy through activation of the insulin-like growth factor 1 receptors [118]. Furthermore, increased insulin levels in the setting of IR could also be important for titin-based cardiomyocyte stiffness as insulin stimulates a shift towards increased expression of the stiff titin N2B isoform [32].

\section{Diabetes mellitus}

The prevalence of DM, especially DMII, is steadily increasing and is expected to reach pandemic proportions in the next few decades [150]. DM is an important risk factor for HF and each $1 \%$ increase in hemoglobin A1c level was associated with an $8 \%$ increase in HF prevalence [118]. Diastolic LV diastolic dysfunction represents the first manifestation of myocardial involvement in DM $[112,151]$. HFpEF patients demonstrate a high prevalence of DMII ranging from $26-45 \%[1,2,18-21,86]$. About $75 \%$ of normotensive, well controlled DMII patients without coronary artery disease show evidence of $\mathrm{LV}$ diastolic dysfunction with echocardiographic tissue Doppler imaging [112]. In a LV endomyocardial biopsy study, compared to non-diabetics, $\mathrm{HFpEF}$ patients with DM had higher diastolic LV stiffness and more severely hypertrophied and stiffer cardiomyocytes [126]. DM induces diastolic LV dysfunction through multiple mechanisms. DM changes the myocardial ECM as evident from enhanced interstitial and perivascular fibrosis, increased expression of collagen type I, and downregulation of collagen-degrading matrix metalloproteinases [119]. These pathologic mechanisms are mediated by hyperglycemia, oxidative stress and elevated aldosterone and AngII levels [119]. In addition to fibrosis, increased myocardial deposition of advanced glycation endproducts (AGEs) also elevates diastolic LV stiffness in DM [120].
AGEs are modifications of proteins or lipids that become nonenzymatically glycated and oxidized after contact with aldose sugars with creation of nearly irreversible cross-links. Formation and accumulation of AGEs is enhanced by hyperglycemia, oxidative stress, aging and hypertension and represent an independent predictor of cardiac death and hospitalization [120]. Increased myocardial AGEs deposition was recently also shown in the myocardial microvasculature of diabetic HFpEF patients [126]. Myocardial AGE deposition augments diastolic LV stiffness by direct and indirect mechanisms, including formation of collagen cross-links, stimulation of collagen production and activation of AGE receptors. In additon, AGEs increase oxidative stress and proinflammatory cytokine release resulting in endothelial dysfunction and reduced NO bioavailability [120].

DM impairs myocardial bioenergetics through a shift from glucose utilization to increased fatty acid oxidation, which leads to myocardial lipotoxicity, uncoupling of mitochondrial oxidative phosphorylation and disturbed contraction/relaxation coupling $[117,125]$. Reduced high-energy phosphate metabolism was shown to parallel LV diastolic dysfunction in well-controlled, normotensive DMII patients without coronary artery disease [122]. Apart from disturbed myocardial energetics, DM also impairs myocardial relaxation through abnormalities in diastolic cardiomyocyte calcium handling [125]. DM induces endothelial dysfunction, reduced NO bioavailability and impaired vasodilator responses through increased systemic inflammation and oxidative stress $[117,125]$. Hyperglycemia induces oxidative stress via several mechanisms, which include glucose autooxidation, formation of AGEs, activation of the polyol pathway and increased levels of free fatty acids and leptin [152]. Previously, hyperglycemia was shown to attenuate PKG expression and activity through PKC dependent activation of NADPH oxidasemediated oxidative stress [127].

\section{Impact of Noncardiac Comorbidities on Myocardial Dysfunction and Remodeling in HFpEF}

Although HFpEF is associated with more cardiovascular abnormalities and worse outcome beyond the level explainable by comorbitidies alone, the rationale for an important involvement of noncardiac comorbidities in myocardial dysfunction and remodeling in HFpEF seems evident. Currently, there is no pharmacological therapy that improves mortality in HFpEF. Lifestyle modifications, such as exercise and weight loss have shown favourable results in high risk patients and could also be of benefit in HFpEF, perhaps in conjunction with existing or novel pharmacological strategies.

\section{Treatment of HFpEF}

\section{Lifestyle interventions}

Exercise training: Exercise training improved exercise capacity and reduced morbidity in HFrEF [153]. A modest outcome benefit with exercise training in HFrEF was also demonstrated in a large meta-analysis and the HF-ACTION trial $[154,155]$. Furthermore, exercise training improves endothelial 
dysfuntion, systemic inflammation and metabolic syndrome [156-158]. Limited data suggest that exercise training attenuates the age-dependent decline in diastolic function [65]. Conversely, exercise training did not favorably reverse cardiac stiffening in sedentary seniors without HF, but it favorably affected LV remodeling, arterial function and aerobic exercise capacity [159]. In two small studies of exercise training in HFpEF patients, 16 weeks of exercise training improved exercise tolerance without altering endothelial function, arterial stiffness or systolic [160] and diastolic function [161]. Enhanced skeletal muscle perfusion and/or oxygen utilization was suggested as a possible mechanism for exercise-mediated improvements in peak oxygen consumption [160]. In the randomized Ex-DHF trial, HFpEF patients randomized to endurance/resistance training demonstrated improved exercise capacity and quality of life [47].

Weight loss: Intentional weight loss in obese patients can improve or prevent many of the obesity-related risk factors for cardiovascular disease [162]. Weight loss ameliorates obesity related cardiac hypertrophy and diastolic dysfunction [163165], while it improves excessive myocardial free fatty acid uptake, oxygen consumption and lowers LV filling pressures through reduction in central blood volume [166,167]. Reducing weight in obesity lowers inflammatory biomarkers and improves endothelial function and insulin sensitivity [168,169]. In normal weight adults, an average weight gain of $4.1 \mathrm{~kg}$ impaired flowmediated dilation, which was restored to baseline when subjects lost this excess weight [170]. In morbidly obese subjects (BMI > $40 \mathrm{~kg} / \mathrm{m}^{2}$ ), weight reduction after bariatric surgery normalized aortic function, reduced LV hypertrophy and improved LV diastolic function [134,171,172], whereas surgical-induced weight loss also improved LV relaxation, myocardial energetics and oxygen consumption [163].

Significant increases in adiponectin levels and reduction in IR were observed in diabetic and nondiabetic patients after 2 months of diet-induced weight loss [173]. A Mediterraneanstyle diet was shown to have beneficial effects on endothelial function in patients with the metabolic syndrome leading to an improvement of vascular inflammatory markers and IR [174]. Weight loss, a Mediterranean-style diet and exercise reduce serum concentrations of IL6, IL7 and IL18 in obese subjects [175]. The benefit of lifestyle modification on metabolic and inflammatory parameters was also recorded in postmenopausal women who after a 2-week high-fibre and low-fat diet together with aerobic exercise, had reduced serum glucose concentrations, improved insulin sensitivity and lowered hsCRP and ICAM-1 levels [176].

\section{Modulation of Renin-Angiotensin-Aldosterone System and beta-Adrenergic Signaling}

Neurohumoral and RAAS activation are centrally involved in the pathogenesis of HF $[177,178]$. These systems are initially able to compensate for the depressed myocardial function and preserve cardiovascular homeostasis. However, their longterm activation has deleterious effects on cardiac structure and performance, leading to cardiac decompensation and HF progression $[177,178]$. Modulation of the RAAS and $\beta$-adrenergic signaling has significantly improved clinical outcome in HFrEF. Despite the rationale for also potential efficacy in HFpEF, modulation of RAAS and beta-adrenergic signaling yielded neutral results in HFpEF populations.

\section{Modulation of renin-angiotensin-aldosterone system (RAAS)}

The RAAS plays a key role in the pathophysiology of HF by controlling cardiovascular, renal and adrenal function by regulating body fluids, electrolyte balance and arterial pressure [179]. Renin, released in the kidney converts angiotensinogen into angiotensin I (AngI), which is then converted to AngII by angiotensin-converting enzyme (ACE) [180]. In addition to converting AngI to AngII, ACE metabolizes bradykinin, an active vasodilator, to an inactive metabolite. AngII is the main effector peptide of the RAAS causing an increase in blood pressure via vasoconstriction and sodium and water retention. It also mediates aldosterone and vasopressin secretion and sympathetic activation $[179,180]$. In addition, AngII induces inflammatory responses, oxidative stress and collagen synthesis, which are importantly involved in maladaptive cardiac remodeling and dysfunction in HFpEF. AngII exerts most of its actions by binding to the AngII type 1 (AT1) and AngII type 2 (AT2) receptors, which elicit distinct responses $[179,180]$. AT1 receptor activation leads to vasoconstriction, sodium reabsorption, aldosterone secretion, sympathetic activation, inflammatory responses and oxidative stress, whereas AT2 receptor stimulation mediates opposite effects, including vasodilation, $\mathrm{NO}$ and bradykinin production and antiproliferative effects [181]. Angiotensin II receptor blockers (ARBs) act by selectively blocking the AT1 receptor, thereby directly blocking the vasoconstrictor and growth effects of AngII [180]. Selective blockade of the AT1 receptor has additional cardiovascular benefits as AngII that is unable to bind to the AT1 receptor stimulates the unaffected AT2 receptor, resulting in vasodilation, growth inhibition and $\mathrm{NO}$ and bradykinin production [181]. ACE inhibitors decrease levels of circulating AngII by inhibiting ACE and reducing the conversion of AngI to AngII [181]. However, ACE inhibitors do not fully prevent conversion of AngI to AngII because other enzymes (chymase and cathepsin G) are capable of synthesizing AngII [180,181]. In addition, ACE inhibitors also interfere with the breakdown of bradykinin, resulting in beneficial increases in vasodilatory bradykinin and NO. Aldosterone is a steroid hormone and downstream effector of AngII, which is mainly synthesized by the adrenal cortex, but is also present in vascular, brain, heart and adipose tissues leading to local autocrine or paracrine effects [103,182]. Aldosterone produces a number of potentially deleterious effects in HFpEF, including sodium and water reabsorption, sympathetic nervous system activation, vasoconstriction, increased oxidative stress with inflammation, remodeling, fibrosis and endothelial dysfunction [103,182]. Targeting the RAAS with ARBs, ACE inhibitors and aldosterone antagonists has long been considered reasonable for HFpEF based on its link to hypertension, fibrosis and fluid imbalance, but despite their clear success in HFrEF, clinical trials with RAAS inhibitors in HFpEF produced neutral outcome results $[25,26,87,88,183]$. 


\section{Modulation of beta-adrenergic signaling}

Sympathetic activation of cardiac beta-adrenergic signaling pathways modulates inotropic, chronotropic and lusitropic responses, providing pivotal control over cardiac reserve responses. These effects are mediated through the 7-transmembrane spanning, G-protein coupled receptors, beta1 $(\beta 1)-$, beta2 ( $\beta 2)$ - and beta3 ( $\beta 3$ )-adrenoceptors ( $\beta A R s)$, which are all present in the human heart $[177,178]$. The $\beta 1 \mathrm{AR}$ is the predominant receptor subtype expressed in the heart and $1 \mathrm{AR}$ expression is downregulated in both HFpEF and HFrEF [184]. Stimulation of $\beta 1$ - and $\beta 2 A R s$ increases cardiac contractility (positive inotropic effect), frequency (positive chronotropic effect) and rate of relaxation (positive lusitropic effect), as well as impulse conduction through the atrioventricular node (positive dromotropic effect) through stimulation of Gs-adenylyl cyclase(AC)-cyclic adenosine monophosphate (cAMP)-PKA signaling $[177,178]$. Unlike $\beta 1 \mathrm{AR}$, which couples only to Gs, $\beta 2 \mathrm{AR}$ also couples to Gi proteins, which has negative effects on AC activity, cAMP synthesis, PKA activation and the inotropic response mediated by Gs. Persistent stimulation of $1 \mathrm{AR}$ and 2AR exhibits distinct outcomes in HF, with chronic stimulation of $\beta 1 \mathrm{AR}$ triggering cardiomyocyte apoptosis [185], whereas persistent stimulation of $\beta 2 \mathrm{AR}$ has cardioprotective effects, primarily mediated by $\beta 2 \mathrm{AR}-\mathrm{Gi}$ coupling [186]. cAMP signaling is compartmentalized [187] and spatial control of signal propagation is paramount for specificity of signaling [188]. Thus, depending on their location, cAMP signals may have different functional effects and changes in the phosphorylation of individual PKA substrates may be either beneficial or harmful, depending on the specific target involved [189]. PKA represents the effector kinase of $\beta 1 A R$ and $\beta 2 A R$ signaling and PKA-mediated phosphorylation of its targets, such as phospholamban, L-type calcium channel, ryanodine receptor, troponin I and titin results in positive inotropic, chronotropic and lusitropic effects and lowering of cardiomyocyte stiffness [177,178,190] (Figure1). B3ARs are predominantly inactive during normal physiological conditions [191], but are upregulated in HF [192], while $\beta 3$ ARs are more resistant than $\beta 1$ - and 2ARs to homologous desensitization [193]. Stimulation of $\beta 3$ ARs exerts a negative inotropic effect opposite to that induced by $\beta 1$ - and $\beta 2 A R s$ through activation of the NO synthase pathway, which results in activation of sGC-cGMPPKG signaling [194]. PKG inhibits $\beta$-adrenergic contractility through crosstalk with cAMP-PKA signaling via modulation of phosphodiesterases (PDEs) type 2 (PDE2) and 3 (PDE3) and decreases myofilament calcium sensitivity via phosphorylation of troponin I [190,195]. PDE2 is a dual substrate esterase with catalytic activity for both cAMP and cGMP $[190,195,196]$. Without concomitant adrenergic stimulation, PDE2 can hydrolyze a cGMP pool coupled to NP/pGC $[190,196]$. However, in the presence of stimulation, cGMP activates PDE2 to reduce cAMP levels and diminish the PKA signal $[190,196]$. The source of cGMP can be both via $\mathrm{NP} / \mathrm{pGC}$ or $\beta 3-\mathrm{AR} / \mathrm{NO} / \mathrm{sGC}$-coupled pathways. In addition, $\beta 3-\mathrm{AR} / \mathrm{NO} / \mathrm{sGC}$-induced cGMP increases the PKA signal through cGMP-mediated inhibition of PDE3-induced hydrolysis of cAMP $[190,196]$. Stimulation of $\beta 3$ ARs could thus represent a therapeutic strategy to increase cardiomyocyte cGMP-
PKG signaling and modulate cAMP-PKA signaling. The third generation beta-blocker, nebivolol, selectively inhibits $\beta 1 \mathrm{ARs}$, but stimulates $\beta 3$ AR-NOS-cGMP-PKG signaling [197]. Nebivolol has negative inotropic effects and stimulates vasodilatation, reverses endothelial dysfunction, favourably modifies hemostatic and fibrinolytic status and has anti-inflammatory and anti-oxidant effects [197]. Unfortunately, compared with placebo, 6 month treatment with nebivolol did not improve exercise capacity in patients with HFpEF in the Effects of Nebivolol on Clinical Symptoms, Exercise Capacity, and Left Ventricular Function in Diastolic Dysfunction (ELANDD) trial [198].

\section{Targeting Disturbed cGMP Signaling}

According to the new HFpEF paradigm, prevalent comorbidities foster a systemic inflammatory state contributing to endothelial dysfunction, oxidative stress and impaired NO bioavailability with downregulation of myocardial NO-cGMP-PKG signaling. Subsequently this chain of events results in myocardial dysfunction and remodeling with increased cardiomyocyte stiffness, hypertrophy and interstitial fibrosis. Therefore targeting defective cGMP-PKG signaling could represent a novel inroad for HFpEF treatment [22] (Figure 4).

\section{NO-donors}

Acute administration of NO donors improves diastolic LV function with an earlier onset of LV relaxation, lower LV peak systolic, end-systolic and end-diastolic pressures, and with rightward displacement of the diastolic LV pressure-volume relation [199]. Aside from effects on inotropy and ventricular compliance, NO is a mediator of myocardial energetics through regulation of mitochondrial respiration, oxygen consumption and substrate utilization [200]. Current ESC HF guidelines accord a class IIa indication for administration of NO donors in patients admitted for acute HF with pulmonary edema without concomitant cardiogenic shock [201]. Unfortunately, long-term use of NO donors is frequently hampered by development of NO resistance [202]. NO resistance largely results from a combination of scavenging of $\mathrm{NO}$ by superoxide and of inactivation of sGC [203]. In addition, chronic treatment with nitrates may cause oxidative stress via increased expression of endothelin, hence potentially exacerbating endothelial dysfunction [204]. Conversely, chronic use of isosorbide dinitrate combined with the antioxidant hydralazine improved outcome in V-HeFT I and A-HeFT trials $[205,206]$. Hydralazine reduces superoxide generation by xanthine oxidase and NADPH oxidase [207]. The clinical characteristics of the A-HeFT HFrEF patients revealed a high prevalence of obesity and DM [208], conditions which are also highly prevalent in HFpEF. Combined use of isosorbide dinitrate and the antioxidant hydralazine could therefore be potentially favorable in HFpEF.

\section{Phosphodiesterase type 5 inhibition (PDE5-I)}

An alternative approach to stimulate cGMP-PKG signaling is to inhibit the action of PDE5, which breaks down cGMP and hence offsets cGMP-PKG signaling (Figure 1). PDE5A inhibitors attenuate adrenergic stimulation [209], reduce ventricularvascular stiffening [209], antagonize maladaptive chamber 
remodeling [210,211], improve endothelial function [212], reduce pulmonary vascular resistance $[211,213,214]$ and lower diastolic LV stiffness in patients with HFrEF [211] and in HFpEF patients with pulmonary hypertension [212]. However, in the multicenter RELAX trial [215], the PDE5 inhibitor sildenafil did not improve exercise capacity in HFpEF patients. Because plasma cGMP levels were not elevated in the sildenafil treated group, questions have arisen as to whether inhibition of cGMP catabolism is effective in settings associated with impaired upstream cGMP generation, such as systemic inflammation, oxidative stress and endothelial dysfunction [216].

\section{sGC activation and stimulation}

Recently, two classes of drugs have been discovered, the sGC activators and SGC stimulators, which target two different redox states of sGC: the NO-sensitive reduced (ferrous) SGC and NOinsensitive oxidized (ferric) sGC respectively [217]. Oxidative stress favours heme-free sGC, which is unresponsive to NO. Hence, oxidative stress synergistically hampers NO-cGMP signaling through sGC oxidation and through ROS-mediated scavenging of NO [218,219], thereby compromising NO-sGC-cGMP mediated signaling $[217,220]$. The sGC stimulators have a dual mode of action; they sensitize sGC to low levels of NO and can stimulate sGC directly in the absence of endogenous NO. Conversely, sGC activators specifically activate the NO-unresponsive, hemefree form of the enzyme irrespective of NO bioavailability $[217,220,221]$. In a nonrandomized proof of concept study, the sGC activator cinaciguat acutely reduced pulmonary capillary and artery pressures, lowered pulmonary and systemic vascular resistance and improved cardiac output in patients admitted for acute decompensated HF [222]. Unfortunately, additional phase IIb studies in acute HF patients, demonstrated cinaciguat to be associated with an excess of non-fatal hypotensive episodes without improvements in dyspnea or cardiac index [223]. The sGC stimulator riociguat improved 6-minute walk distance, NP levels and functional class in patients with WHO Group 1 and Group 4 pulmonary hypertension [224,225]. A phase IIb study in HFrEF patients testing riociguat failed to show a benefit for the primary endpoint of pulmonary artery pressure, but did show improvements in pulmonary and systemic vascular resistance, cardiac output, stroke volume and quality of life [226]. Currently, a trial with a once-daily oral sGC stimulator in HFpEF, BAY1021189 is under way.

\section{Stimulation of NP-cGMP signaling}

BNP-pGC signaling failed to normalize cGMP content in HFpEF myocardium [37]. This failure relates to the low diastolic wall stress prevailing in a concentrically remodeled LV [227], and is consistent with the lower BNP levels frequently observed in HFpEF patients [52,228,] and supports use in HFpEF of drugs that simulate BNP production or reduce BNP breakdown [229]. The synthetic NP nesiritide was shown to acutely reduce pulmonary capillary wedge pressure and systemic vascular resistance, while increasing cardiac index and stroke volume index in HFrEF patients [230]. Acute NP administration was recently reported to lower diastolic LV stiffness and to increase myocardial titin phosphorylation in an old hypertensive HFpEF dog model [231] but failed to improve clinical endpoints in a large, randomized clinical trial of acutely decompensated HF patients with either $\mathrm{LVEF}<40 \%$ and $\mathrm{LVEF} \geq 40 \%$ [232].

Neprilysin enzymatically degrades BNP but not N-terminal pro-B-type NP (NT-proBNP), and compounds combining nepilysin inhibition with RAAS blockade are actively being tested in human HF. Recently, LCZ696, a first-in-class angiotensin-receptor/ neprilysin inhibitor was tested in 301 patients with HFpEF. Compared with valsartan, LCZ696 resulted in greater reductions in NT-proBNP at 12 weeks, improved LA remodeling and was well tolerated [229].

\section{Statins}

The new HFPEF paradigm also supports use of statins. Statins exert rapid and direct effects on endothelial redox balance, which are independent of low-density lipoprotein lowering and consist of reduced superoxide anion production and restored NO bioavailability [233]. These effects reach adjacent cardiomyocytes and fibroblasts as evident in experimental hypertension or hypercholesterolemia from regression of LV hypertrophy, prevention of myocardial fibrosis and amelioration of diastolic LV dysfunction [234]. A retrospective analysis of a recent clinical study looking at myocardial nitrotyrosine content, PKG activity, hypertrophy and stiffness in HFpEF patients [37] revealed statin treated patients to have less nitrotyrosine, more PKG activity, less cardiomyocyte hypertrophy and lower cardiomyocyte stiffness. These findings are in line with the positive outcome of a small study that showed statin use to lower mortality of HFpEF patients [235]. A neutral outcome of statin use was however also reported in a large randomized heart failure trial in a subgroup of patients with relatively preserved LV EF (> 40\%) [236].

\section{Relaxin}

Serelaxin, a recombinant form of human relaxin-2, administered to acute HF patients caused an improvement of symptoms and prevention of organ damage with a reduction in 180-day mortality compared with placebo [237,238]. The peptide hormone relaxin, which is known as a reproductive hormone also has potential beneficial actions in HF including stimulation of systemic endothelial function with increased NO bioavailability and inhibition of inflammation and fibrosis [239]. In HFpEF patients, serelaxin was well tolerated and improved dyspnoea and 180-day mortality [240]. However, the RELAXAHF study was not primarily designed and powered to assess mortality [237] and the subgroup of HFpEF patients comprised 275 patients. Therefore, the effects of serelaxin on HFpEF patients should be confirmed by subsequent trials.

\section{Conclusion}

HFpEF is increasingly prevalent and is associated with a significant morbidity and mortality, while its pathophysiology and therapy remain uncertain. Besides diastolic LV dysfunction, numerous other mechanisms are thought to be involved in its pathophysiology, including impaired systolic rest and/or reserve function, abnormal ventricular-arterial coupling, myocardial energetic deficiency, pulmonary hypertension, chronotropic 
incompetence, inflammation, oxidative stress and endothelial dysfunction. In addition, HFpEF patients often present with a multitude of comorbidities which themselves are also known to elicit detrimental responses in the cardiovascular system. The new HFpEF paradigm proposes an important contributory role of noncardiac comorbidities to myocardial dysfunction and remodeling. In $\mathrm{HFpEF}$, comorbidities contribute to a systemic inflammatory state, which induces oxidative stress in the coronary microvascular endothelium. This reduces myocardial NO bioavailability and leads to reduced PKG activity in cardiomyocytes, which therefore become stiff and hypertrophied. Furthermore, increased age and postmenopausal hormonal changes could result in additive maladaptive cardiovascular structural and functional changes. Hence, as proposed by the new paradigm of HFpEF, noncardiac comorbidities could certainly represent prime suspects in eliciting coronary microvascular endothelial dysfunction and downregulation of myocardial NOcGMP-PKG signaling [22].

\section{Future Perspectives}

HFpEF represents a complex disorder with a heterogeneous constellation of comorbidities and underlying pathogenic mechanisms and poses a formidable challenge for clinicians and translational researchers. Many issues regarding underlying pathophysiological mechanisms remain unresolved. For instance, patients with substantial diastolic dysfunction with or without structural heart disease in the setting of hypertensive heart disease may behave differently from those with chronotropic incompetence or from those with normal blood pressure but inflammatory activation in the setting of metabolic risk factors. In addition, pathogenic mechanisms may vary in the course of HFpEF disease trajectory and could therefore differentially influence structural and functional myocardial dysfunction at different time courses of the disease. Furthermore, the additive role of pre-existing or newly developing non-cardiac comorbidities on structural and functional remodeling in HFpEF is incompletely understood. Therefore, improved subclassification of HFpEF patients, increased procurement of HFpEF myocardial tissue, for instance through LV endomyocardial biopsy procurement, and improvement in experimental HFpEF models are important future goals in enhancing our understanding of HFpEF pathophysiology. Stimulation of crosstalk and formation of collaborative networks between translational researchers and clinicians is of great interest to enhance insight into structural and functional cardiovascular dysfunction in the setting of coexisting variable pathogenic mechanisms and comorbidities in HFpEF patients.

\section{Acknowledgment}

Dr.van Heerebeek and Dr.Paulus are supported by a grantfrom the European Commission (FP7-Health-2010;MEDIA-261409).

\section{References}

1. Owan TE, Hodge DO, Herges RM, Jacobsen SJ, Roger VL, Redfield MM. Trends in prevalence and outcome of heart failure with preserved ejection fraction. N Engl J Med. 2006; 355(3):251-259.
2. Steinberg BA, Zhao X, Heidenreich PA, Peterson ED, Bhatt DL, Cannon $\mathrm{CP}$, et al; Get With the Guidelines Scientific Advisory Committee and Investigators. Trends in patients hospitalized with heart failure and preserved left ventricular ejection fraction: prevalence, therapies, and outcomes. Circulation. 2012; 126(1):65-75. doi: 10.1161/ CIRCULATIONAHA.111.080770.

3. Meta-analysis Global Group in Chronic Heart Failure (MAGGIC). The survival of patients with heart failure with preserved or reduced left ventricular ejection fraction: an individual patient data meta-analysis. Eur Heart J. 2012; 33(14):1750-1757. doi: 10.1093/eurheartj/ehr254.

4. Paulus WJ, Tschöpe C, Sanderson JE, Rusconi C, Flachskampf FA, Rademakers FE, et al. How to diagnose diastolic heart failure: a consensus statement on the diagnosis of heart failure with normal left ventricular ejection fraction by the Heart Failure and Echocardiography Associations of the European Society of Cardiology. Eur Heart J. 2007; 28(20):2539-2550.

5. Borlaug BA, Paulus WJ. Heart failure with preserved ejection fraction: pathophysiology, diagnosis and treatment. Eur Heart J. 2011; 32(6):670-679. doi: 10.1093/eurheartj/ehq426.

6. Komajda M, Lam CS. Heart failure with preserved ejection fraction: a clinical dilemma. Eur Heart J. 2014; 35(16):1022-1032. doi: 10.1093/ eurheartj/ehu067.

7. Yu CM, Lin H, Yang H, Kong SL, Zhang Q, Lee SW. Progression of systolic abnormalities in patients with "isolated" diastolic heart failure and diastolic dysfunction. Circulation. 2002; 105(10):1195-1201.

8. Fukuta H, Little WC. Contribution of systolic and diastolic abnormalities to heart failure with a normal and a reduced ejection fraction. Prog Cardiovasc Dis. 2007; 49(4):229-240.

9. Borlaug BA, Lam CS, Roger VL, Rodeheffer RJ, Redfield MM. Contractility and ventricular systolic stiffening in hypertensive heart disease insights into the pathogenesis of heart failure with preserved ejection fraction. J Am Coll Cardiol. 2009; 54(5):410-418. doi: 10.1016/j.jacc.2009.05.013.

10. Kawaguchi M, Hay I, Tetics B, Kass DA. Combined ventricular systolic and arterial stiffening in patients with heart failure and preserved ejection fraction: implications for systolic and diastolic reserve limitations. Circulation. 2003; 107(5):714-720.

11. Borlaug BA, Kass DA. Ventricular-vascular interaction in heart failure. Heart Fail Clin. 2008; 4(1):23-36. doi: 10.1016/j.hfc.2007.10.001.

12. Phan TT, Abozguia K, Nallur Shivu G, Mahadevan G, Ahmed I, Williams $\mathrm{L}$, et al. Heart failure with preserved ejection fraction is characterized by dynamic impairment of active relaxation and contraction of the left ventricle on exercise and associated with myocardial energy deficiency. J Am Coll Cardiol. 2009; 54(5):402-409. doi: 10.1016/j. jacc.2009.05.012.

13. Borlaug BA, Olson TP, Lam CS, Flood KS, Lerman A, Johnson BD, et al. Global cardiovascular reserve dysfunction in heart failure with preserved ejection fraction. J Am Coll Cardiol. 2010; 56(11):845-854. doi: 10.1016/j.jacc.2010.03.077.

14. Borlaug BA, Melenovsky V, Russell SD, Kessler K, Pacak K, Becker LC, et al. Impaired chronotropic and vasodilator reserves limit exercise capacity in patients with heart failure and a preserved ejection fraction. Circulation. 2006; 114(20):2138-2147.

15. Borlaug BA, Nishimura RA, Sorajja P, Lam CS, Redfield MM. Exercise hemodynamics enhance diagnosis of early heart failure with preserved ejection fraction. Circ Heart Fail. 2010; 3(5):588-595. doi: 10.1161/CIRCHEARTFAILURE.109.930701. 
16. Kjaergaard J, Akkan D, Iversen KK, Kjoller E, Køber L, Torp-Pedersen C, et al. Prognostic importance of pulmonary hypertension in patients with heart failure. Am J Cardiol. 2007; 99(8):1146-1150.

17. Lam CS, Roger VL, Rodeheffer RJ, Borlaug BA, Enders FT, Redfield MM. Pulmonary hypertension in heart failure with preserved ejection fraction: a community-based study. J Am Coll Cardiol. 2009; 53(13):1119-1126. doi: 10.1016/j.jacc.2008.11.051.

18. Yancy CW, Lopatin M, Stevenson LW, De Marco T, Fonarow GC, ADHERE Scientific Advisory Committee and Investigators. Clinical presentation, management, and in-hospital outcomes of patients admitted with acute decompensated heart failure with preserved systolic function: A Report from the Acute Decompensated Heart Failure National Registry (ADHERE) Database. J Am Coll Cardiol. 2006; 47(1):76-84.

19. Fonorow GC, Stough WG, Abraham WT, Albert NM, Gheorghiade M, Greenberg BH, et al. OPTIMIZE-HF Investigators and Hospitals. Characteristics, treatments and outcomes of patients with preserved systolic function hospitalized for heart failure: a report from the OPTIMIZE-HF Registry. J Am Coll Cardiol. 2007; 50(8):768-777.

20. Lam CS, Donal E, Kraigher-Krainer E, Vasan RS. Epidemiology and clinical course of heart failure with preserved ejection fraction. Eur J Heart Fail. 2011; 13(1):18-28. doi: 10.1093/eurjhf/hfq121.

21. Ather S, Chan W, Bozkurt B, Aguilar D, Ramasubbu K, Zachariah AA, et al. Impact of noncardiac comorbidities on morbidity and mortality in a predominantly male population with heart failure and preserved versus reduced ejection fraction. J Am Coll Cardiol. 2012; 59(11):9981005. doi: 10.1016/j.jacc.2011.11.040.

22. Paulus WJ, Tschöpe C. A novel paradigm for heart failure with preserved ejection fraction: comorbidities drive myocardial dysfunction and remodeling through coronary microvascular endothelial inflammation. J Am Coll Cardiol. 2013; 62(4):263-271. doi: 10.1016/j.jacc.2013.02.092.

23. Zile MR, Baicu CF, Gaasch WH. Diastolic heart failure - abnormalities in active relaxation and passive stiffness of the left ventricle. $\mathrm{N}$ Engl J Med. 2004; 350(19):1953-1959.

24. Westermann D, Kasner M, Steendijk P, Spillmann F, Riad A, Weitmann K, Hoffmann W, Poller W, Pauschinger M, Schultheiss HP, Tschöpe C. Role of left ventricular stiffness in heart failure with normal ejection fraction. Circulation. 2008; 117(16):2051-2060. doi: 10.1161/ CIRCULATIONAHA.107.716886.

25. Pitt B, Pfeffer MA, Assmann SF, Boineau R, Anand IS, Claggett B, et al. TOPCAT Investigators. Spironolactone for heart failure with preserved ejection fraction. N Engl J Med. 2014; 370(15):1383-1392. doi: 10.1056/NEJMoa1313731.

26. Massie BM, Carson PE, McMurray JJ, Komajda M, McKelvie R, Zile MR, et al. I-PRESERVE Investigators. Irbesartan in patients with heart failure and preserved ejection fraction. N Engl J Med. 2008; 359(23):24562467. doi: $10.1056 /$ NEJMoa0805450.

27. van Heerebeek L, Borbely A, Niessen HWM, Bronzwaer JG, van der Velden J, Stienen GJ, et al. Myocardial structure and function differ in systolic and diastolic heart failure. Circulation. 2006; 113(16):19661973.

28. Martos R, Baugh J, Ledwidge M, O'Loughlin C, Conlon C, Patle A, et al. Diastolic heart failure: evidence of increased myocardial collagen turnover linked to diastolic dysfunction. Circulation. 2007; 115(7):888-895.

29. González A, López B, Querejeta R, Zubillaga E, Echeverría T, Díez J.
Filling pressures and collagen metabolism in hypertensive patients with heart failure and normal ejection fraction. Hypertension. 2010; 55(6):1418-1424. doi: 10.1161/HYPERTENSIONAHA.109.149112.

30. Kasner M, Westermann D, Lopez B, Gaub R, Escher F, Kühl U, et al. Diastolic tissue Doppler indexes correlate with the degree of collagen expression and cross-linking in heart failure and normal ejection fraction. J Am Coll Cardiol. 2011; 57(8):977-985. doi: 10.1016/j. jacc.2010.10.024.

31. Borbely A, van der Velden J, Papp Z, Bronzwaer JG, Edes I, Stienen GJ, et al. Cardiomyocyte stiffness in diastolic heart failure. Circulation. 2005; 111(6):774-781.

32. Linke WA, Hamdani N. Gigantic business: titin properties and function through thick and thin. Circ Res. 2014; 114(6):1052-1068. doi: 10.1161/CIRCRESAHA.114.301286.

33. Krüger M, Linke WA. Protein kinase-A phosphorylates titin in human heart muscle and reduces myofibrillar passive tension. J Muscle Res Cell Motil. 2006; 27(5-7):435-444.

34. Krüger M, Kötter S, Grützner A, Lang P, Andresen C, Redfield MM, et al. Protein kinase $\mathrm{G}$ modulates human myocardial passive stiffness by phosphorylation of the titin springs. Circ Res. 2009; 104(1):87-94. doi: 10.1161/CIRCRESAHA.108.184408.

35. Hidalgo C, Hudson B, Bogomolovas J, Zhu Y, Anderson B, Greaser $\mathrm{M}$, et al. PKC phosphorylation of titin's PEVK element. A novel and conserved pathway for modulating myocardial stiffness. Circ Res. 2009; 105(7):631-638. doi: 10.1161/CIRCRESAHA.109.198465.

36. Borbely A, Falcao-Pires I, van Heerebeek, Hamdani N, Edes I, Gavina C, et al. Hypophosphorylation of the stiff N2B titin isoform raises cardiomyocyte resting tension in failing human myocardium. Circ Res. 2009; 104(6):780-786. doi: 10.1161/CIRCRESAHA.108.193326.

37.van Heerebeek L, Hamdani N, Falcao-Pires I, Leite-Moreira AF, Begieneman MPV, Bronzwaer JGF, et al. Low myocardial protein kinase $\mathrm{G}$ activity in heart failure with preserved ejection fraction. Circulation. 2012; 126(7):830-839. doi: 10.1161/CIRCULATIONAHA.111.076075.

38. Takimoto E. Cyclic GMP-dependent signaling in cardiac myocytes. Circ J. 2012; 76(8):1819-1825.

39. Akiyama E, Sugiyama S, Matsuzawa Y, Konishi M, Suzuki H, Nozaki T, et al. Incremental prognostic significance of peripheral endothelial dysfunction in patients with heart failure with normal left ventricular ejection fraction. J Am Coll Cardiol. 2012; 60(18):1778-1886. doi: 10.1016/j.jacc.2012.07.036.

40. Westermann D, Lindner D, Kasner M, Zietsch C, Savvatis K, Escher F, et al. Cardiac inflammation contributes to changes in the extracellular matrix in patients with heart failure and normal ejection fraction. Circ Heart Fail. 2011; 4(1):44-52. doi: 10.1161/ CIRCHEARTFAILURE.109.931451.

41. Vane JR, Anggård EE, Botting RM. Regulatory functions of the vascular endothelium. N Engl J Med. 1990; 323(1):27-36.

42. Savoia C, Schiffrin EL. Vascular inflammation in hypertension and diabetes: molecular mechanisms and therapeutic interventions. Clin Sci(Lond). 2007; 112(7):375-384.

43. Lam CS, Brutsaert DL. Endothelial dysfunction: a pathophysiologic factor in heart failure with preserved ejection fraction. J Am Coll Cardiol. 2012; 60(18):1787-1789. doi: 10.1016/j.jacc.2012.08.004.

44. Hundley WG, Kitzman DW, Morgan TM, Hamilton CA, Darty SN, Stewart KP, et al. Cardiac cycle-dependent changes in aortic area and distensibility are reduced in older patients with isolated diastolic 
heart failure and correlate with exercise intolerance. J Am Coll Cardiol. 2001; 38(3):796-802.

45. Lam CS, Roger VL, Rodeheffer RJ, Bursi F, Borlaug BA, Ommen SR, et al. Cardiac structure and ventricular-vascular function in persons with heart failure and preserved ejection fraction from Olmsted County, Minnesota. Circulation. 2007; 115(15):1982-1990.

46. Haykowsky MJ, Brubaker PH, Stewart KP, Morgan TM, Eggebeen J, Kitzman DW. Effect of endurance training on the determinants of peak exercise oxygen consumption in elderly patients with stable compensated heart failure and preserved ejection fraction. J Am Coll Cardiol. 2012; 60(2):120-128. doi: 10.1016/j.jacc.2012.02.055.

47. Edelmann F, Gelbrich G, Düngen HD, Fröhling S, Wachter R, Stahrenberg R, et al. Exercise training improves exercise capacity and diastolic function in patients with heart failure with preserved ejection fraction: results of the Ex-DHF (Exercise training in Diastolic Heart Failure) pilot study. J Am Coll Cardiol. 2011; 58(17):1780-1791. doi: 10.1016/j.jacc.2011.06.054.

48. Collier P, Watson CJ, Voon V, Phelan D, Jan A, Mak G, Martos R, Baugh JA, Ledwidge MT, McDonald KM. Can emerging biomarkers of myocardial remodelling identify asymptomatic hypertensive patients at risk for diastolic dysfunction and diastolic heart failure? Eur J Heart Fail. 2011; 13(10):1087-1095. doi: 10.1093/eurjhf/hfr079.

49. Kalogeropoulos A, Georgiopoulou V, Psaty BM, Rodondi N, Smith $\mathrm{AL}$, Harrison DG; Health ABC Study Investigators. Inflammatory markers and incident heart failure risk in older adults: the Health $A B C$ (Health, Aging, and Body Composition) study. J Am Coll Cardiol. 2010; 55(19):2129-2137. doi: 10.1016/j.jacc.2009.12.045.

50. Tamaki S, Mano T, Sakata Y, Ohtani T, Takeda Y, Kamimura D, et al. Interleukin-16 promotes cardiac fibrosis and myocardial stiffening in heart failure with preserved ejection fraction. PLoS One. 2013; 8(7):e68893. doi: 10.1371/journal.pone.0068893.

51. van der Velde AR, Gullestad L, Ueland T, Aukrust P, Guo Y, Adourian A, et al. Prognostic value of changes in galectin-3 levels over time in patients with heart failure: data from CORONA and COACH. Circ Heart Fail. 2013; 6(2):219-226. doi: 10.1161/CIRCHEARTFAILURE.112.000129.

52. de Boer RA, Lok DJ, Jaarsma T, van der Meer P, Voors AA, Hillege HL, et al. Predictive value of plasma galectin-3 levels in heart failure with reduced and preserved ejection fraction. Ann Med. 2011; 43(1):60-68. doi: $10.3109 / 07853890.2010 .538080$.

53. Campbell RT, Jhund PS, Castagno D, Hawkins NM, Petrie MC McMurray JJ. What have we learned about patients with heart failure and preserved ejection fraction from DIG-PEF, CHARM-preserved, and I-PRESERVE? J Am Coll Cardiol. 2012; 60(23):2349-2356. doi: 10.1016/j.jacc.2012.04.064.

54. Mohammed SF, Borlaug BA, Roger VL, Mirzoyev SA, Rodeheffer RJ, Chirinos JA, et al. Comorbidity and ventricular and vascular structure and function in heart failure with preserved ejection fraction: a community-based study. Circ Heart Fail. 2012; 5(6):710-719. doi: 10.1161/CIRCHEARTFAILURE.112.968594.

55. Bishu K, Deswal A, Chen HH, LeWinter MM, Lewis GD, Semigran MJ, et al. Biomarkers in acutely decompensated heart failure with preserved or reduced ejection fraction. Am Heart J. 2012; 164(5):763-770. doi: 10.1016/j.ahj.2012.08.014

56. Jessup M, Abraham WT, Casey DE, Feldman AM, Francis GS, Ganiats TG, et al. 2009 focused update: ACCF/AHA Guidelines for the Diagnosis and Management of Heart Failure in Adults: a report of the American College of Cardiology Foundation/American Heart Association Task Force on Practice Guidelines: developed in collaboration with the
International Society for Heart and Lung Transplantation. Circulation. 2009; 119:1977-2016. doi: 10.1161/CIRCULATIONAHA.109.192064.

57. Strait JB, Lakatta EG. Aging-associated cardiovascular changes and their relationship to heart failure. Heart Fail Clin. 2012; 8(1):143-164. doi: 10.1016/j.hfc.2011.08.011.

58. Levy D, Garrison RJ, Savage DD, Kannel WB, Castelli WP. Prognostic implications of echocardiographically determined left ventricular mass in the Framingham Heart Study. N Engl J Med. 1990; 322(22):1561-1566.

59. Olivetti G, Melissari M, Capasso JM, Anversa P. Cardiomyopathy of the aging human heart. Myocyte loss and reactive cellular hypertrophy. Circ Res. 1991; 68(6):1560-1568.

60. Lakatta EG, Levy D. Arterial and cardiac aging: major shareholders in cardiovascular disease enterprises: Part II: the aging heart in health: links to heart disease. Circulation. 2003; 107(2):346-354.

61. Rodeheffer RJ, Gerstenblith G, Beard E, Fleg JL, Becker LC, Weisfeldt ML, et al. Postural changes in cardiac volumes in men in relation to adult age. Exp Gerontol. 1986; 21(4-5):367-378.

62. Lakatta EG. Cardiovascular regulatory mechanisms in advanced age. Physiol Rev. 1993; 73(2):413-467.

63. Lakatta EG, Levy D. Arterial and cardiac aging: major shareholders in cardiovascular disease enterprises: Part I: aging arteries: a "set up" for vascular disease. Circulation. 2003; 107(1):139-146.

64. Franklin SS, Larson MG, Khan SA, Wong ND, Leip EP, Kannel WB, et al. Does the relation of blood pressure to coronary heart disease risk change with aging? The Framingham Heart Study. Circulation. 2001; 103(9):1245-1249.

65. Arbab-Zadeh A, Dijk E, Prasad A, Fu Q, Torres P, Zhang R, et al. Effect of aging and physical activity on left ventricular compliance. Circulation. 2004; 110(13):1799-1805.

66. Tschöpe C, Bock CT, Kasner M, Noutsias M, Westermann D, Schwimmbeck PL, et al. High prevalence of cardiac parvovirus B19 infection in patients with isolated left ventricular diastolic dysfunction. Circulation. 2005; 111(7):879-886.

67. Brutsaert DL. Cardiac endothelial-myocardial signaling: its role in cardiac growth, contractile performance, and rhythmicity. Physiol Rev. 2003; 83(1):59-115.

68. Lam CS, Carson PE, Anand IS, Rector TS, Kuskowski M, Komajda $M$, et al. Sex differences in clinical characteristics and outcomes in elderly patients with heart failure and preserved ejection fraction: the Irbesartan in Heart Failure with Preserved Ejection Fraction (I-PRESERVE) trial. Circ Heart Fail. 2012; 5(5):571-578.

69. Kenchaiah S, Evans JC, Levy D, Wilson PW, Benjamin EJ, Larson MG, et al. Obesity and the risk of heart failure. N Engl J Med. 2002; 347(5):305-313.

70. Peterson LR, Herrero P, Schechtman KB, Racette SB, Waggoner AD, Kisrieva-Ware Z, et al. Effect of obesity and insulin resistance on myocardial substrate metabolism and efficiency in young women. Circulation. 2004; 109(18):2191-2196.

71. Redfield MM, Jacobsen SJ, Borlaug BA, Rodeheffer RJ, Kass DA. Ageand gender-related ventricular-vascular stiffening: a communitybased study. Circulation. 2005; 112(15):2254-2262.

72. Borlaug BA, Redfield MM, Melenovsky V, Kane GC, Karon BL, Jacobsen SJ, et al. Longitudinal changes in left ventricular stiffness: a community-based study. Circ Heart Fail. 2013; 6(5):944-952. doi: 10.1161/CIRCHEARTFAILURE.113.000383. 
73. Regitz-Zagrosek V, Brokat S, Tschope C. Role of gender in heart failure with normal left ventricular ejection fraction. Prog Cardiovasc Dis. 2007; 49(4):241-251.

74. Agarwal SK, Heiss G, Barr RG, Chang PP, Loehr LR, Chambless LE, et al. Airflow obstruction, lung function, and risk of incident heart failure: the Atherosclerosis Risk in Communities (ARIC) study. Eur J Heart Fail. 2012; 14(4):414-422. doi: 10.1093/eurjhf/hfs016.

75. Lam CS, Lyass A, Kraigher-Krainer E, Massaro JM, Lee DS, Ho JE, et al. Cardiac dysfunction and noncardiac dysfunction as precursors of heart failure with reduced and preserved ejection fraction in the community. Circulation. 2011; 124(1):24-30. doi: 10.1161/ CIRCULATIONAHA.110.979203.

76. Barr RG, Bluemke DA, Ahmed FS, Carr JJ, Enright PL, Hoffman EA, et al. Percent emphysema, airflow obstruction, and impaired left ventricular filling. N Engl J Med. 2010; 362(3):217-227. doi: 10.1056/ NEJMoa0808836.

77. Dunlay SM, Weston SA, Redfield MM, Killian JM, Roger VL. Anemia and heart failure: a community study. Am J Med. 2008; 121(8):726-732. doi: 10.1016/j.amjmed.2008.03.039.

78. Muzzarelli S, Leibundgut G, Maeder MT, Rickli H, Handschin R, Gutmann M, et al; TIME-CHF Investigators. Predictors of early readmission or death in elderly patients with heart failure. Am Heart J. 2010; 160(2):308-314. doi: 10.1016/j.ahj.2010.05.007.

79. Groenveld HF, Januzzi JL, Damman K, van Wijngaarden J, Hillege HL, van Veldhuisen DJ, et al. Anemia and mortality in heart failure patients a systematic review and meta-analysis. J Am Coll Cardiol. 2008; 52(10):818-827. doi: 10.1016/j.jacc.2008.04.061.

80. Kleijn L, Belonje AM, Voors AA, De Boer RA, Jaarsma T, Ghosh S, et al. Inflammation and anaemia in a broad spectrum of patients with heart failure. Heart. 2012; 98(16):1237-1241. doi: 10.1136/ heartjnl-2012-301954.

81. Westenbrink BD, Voors AA, de Boer RA, Schuringa JJ, Klinkenberg $\mathrm{T}$, van der Harst $\mathrm{P}$, et al. Bone marrow dysfunction in chronic heart failure patients. Eur J Heart Fail. 2010; 12(7):676-684. doi: 10.1093/ eurjhf/hfq061.

82. Nanas JN, Matsouka C, Karageorgopoulos D, Leonti A, Tsolakis E, Drakos SG, et al. Etiology of anemia in patients with advanced heart failure. J Am Coll Cardiol. 2006; 48(12):2485-2489.

83. Macdougall IC, Canaud B, de Francisco AL, Filippatos G, Ponikowski P, Silverberg D, et al. Beyond the cardiorenal anaemia syndrome: recognizing the role of iron deficiency. Eur J Heart Fail. 2012; 14(8):882-886. doi: 10.1093/eurjhf/hfs056.

84. Hillege HL, Nitsch D, Pfeffer MA, Swedberg K, McMurray JJ, Yusuf S, et al; Candesartan in Heart Failure: Assessment of Reduction in Mortality and Morbidity (CHARM) Investigators. Renal function as a predictor of outcome in a broad spectrum of patients with heart failure. Circulation. 2006; 113(5):671-678.

85. Colombo PC, Ganda A, Lin J, Onat D, Harxhi A, Iyasere JE, et al Inflammatory activation: cardiac, renal, and cardio-renal interactions in patients with the cardiorenal syndrome. Heart Fail Rev. 2012; 17(2):177-190. doi: 10.1007/s10741-011-9261-3

86. Bhatia RS, Tu JV, Lee DS, Austin PC, Fang J, Haouzi A, Gong Y, Liu PP. Outcome of heart failure with preserved ejection fraction in a population-based study. N Engl J Med. 2006; 355(3):260-269.

87. Cleland JG, Tendera M, Adamus J, Freemantle N, Polonski L, Taylor J; PEP-CHF Investigators. The perindopril in elderly people with chronic heart failure (PEP-CHF) study. Eur Heart J. 2006; 27(19):2338-2345.
88. Yusuf S, Pfeffer MA, Swedberg K, Granger CB, Held P, McMurray JJV, et al; CHARM Investigators and Committees. Effects of candesartan in patients with chronic heart failure and preserved left-ventricular ejection fraction: the CHARM-Preserved Trial. Lancet. 2003. 362(9386):777-781.

89. McMurray JJ, Carson PE, Komajda M, McKelvie R, Zile MR, Ptaszynska $A$, et al. Heart failure with preserved ejection fraction: clinical characteristics of 4133 patients enrolled in the I-PRESERVE trial. Eur J Heart Fail. 2008; 10(2):149-156. doi: 10.1016/j.ejheart.2007.12.010.

90. Levy D, Larson MG, Vasan RS, Kannel WB, Ho KK. The progression from hypertension to congestive heart failure. JAMA. 1996; 275(20):15571562.

91. Fischer M, Baessler A, Hense HW, Hengstenberg C, Muscholl M, Holmer S, et al. Prevalence of left ventricular diastolic dysfunction in the community. Results from a Doppler echocardiographic-based survey of a population sample. Eur Heart J. 2003; 24(4):320-328.

92. Leite-Moreira AF. Current perspectives in diastolic dysfunction and diastolic heart failure. Heart. 2006; 92(5):712-718.

93. Müller-Brunotte R, Kahan T, López B, Edner M, González A, Díez J, et al. Myocardial fibrosis and diastolic dysfunction in patients with hypertension: results from the Swedish Irbesartan Left Ventricular Hypertrophy Investigation versus Atenolol (SILVHIA). J Hypertens. 2007; 25(9):1958-1966.

94. Kai H, Kuwahara F, Tokuda K, Imaizumi T. Diastolic dysfunction in hypertensive hearts: roles of perivascular inflammation and reactive myocardial fibrosis. Hypertens Res. 2005; 28(6):483-490.

95. Hart CY, Meyer DM, Tazelaar HD, Grande JP, Burnett JC Jr, Housmans PR, et al. Load versus humoral activation in the genesis of early hypertensive heart disease. Circulation. 2001; 104(2):215-220.

96. Solomon SD, Janardhanan R, Verma A, Bourgoun M, Daley WL, Purkayastha D, et al; Valsartan In Diastolic Dysfunction (VALIDD) Investigators. For the Valsartan In Diastolic Dysfunction (VALIDD) Investigators. Effect of angiotensin receptor blockade and antihypertensive drugs on diastolic function in patients with hypertension and diastolic dysfunction: a randomised trial. Lancet. 2007; 369(9579):2079-2087.

97. Chirinos JA, Segers P, Gupta AK, Swillens A, Rietzschel ER, De Buyzere ML, et al. Time-varying myocardial stress and systolic pressure-stress relationship: role in myocardial-arterial coupling in hypertension. Circulation. 2009; 119(21):2798-807. doi: 10.1161/ CIRCULATIONAHA.108.829366.

98. Cohen RA, Tong X. Vascular oxidative stress: the common link in hypertensive and diabetic vascular disease. J Cardiovasc Pharmacol. 2010; 55(4):308-316.

99. Preston RA, Ledford M, Materson BJ, Baltodano NM, Memon A, Alonso A. Effects of severe, uncontrolled hypertension on endothelial activation: soluble vascular cell adhesion molecule-1, soluble intercellular adhesion molecule-1 and von Willebrand factor. J Hypertens. 2002; 20(5):871-877.

100. Sciarretta S, Ferrucci A, Ciavarella GM, De Paolis P, Venturelli V, Tocci G, et al. Markers of inflammation and fibrosis are related to cardiovascular damage in hypertensive patients with metabolic syndrome. Am J Hypertens. 2007; 20(7):784-791.

101. Hummel SL, Seymour EM, Brook RD, Kolias TJ, Sheth SS, Rosenblum $\mathrm{HR}$, et al. Low-sodium dietary approaches to stop hypertension diet reduces blood pressure, arterial stiffness, and oxidative stress in hypertensive heart failure with preserved ejection 
fraction. Hypertension. 2012; 60(5):1200-1206. doi: 10.1161/ HYPERTENSIONAHA.112.202705.

102. Tian N, Gu JW, Jordan S, Rose RA, Hughson MD, Manning RD Jr. Immune suppression prevents renal damage and dysfunction and reduces arterial pressure in salt-sensitive hypertension. Am J Physiol Heart Circ Physiol. 2007; 292(2):H1018-1025.

103. Whaley-Connell A, Johnson MS, Sowers JR. Aldosterone: role in the cardiometabolic syndrome and resistant hypertension. Prog Cardiovasc Dis. 2010; 52(5):401-409. doi: 10.1016/j. pcad.2009.12.004.

104. Kim JA, Wei Y, Sowers JR. Role of mitochondrial dysfunction in insulin resistance. Circ Res. 2008; 102(4):401-414. doi: 10.1161/ CIRCRESAHA.107.165472.

105. Van Gaal LF, Mertens IL, De Block CE. Mechanisms linking obesity with cardiovascular disease. Nature. 2006; 444(7121):875-880.

106. Stritzke J, Markus MR, Duderstadt S, Lieb W, Luchner A, Döring A et al. The aging process of the heart: obesity is the main risk factor for left atrial enlargement during aging. J Am Coll Cardiol. 2009; 54(21):1982-1989. doi: 10.1016/j.jacc.2009.07.034.

107. Horwich TB, Fonarow GC. Glucose, obesity, metabolic syndrome and diabetes. J Am Coll Cardiol. 2010; 55(4):283-293. doi: 10.1016/j. jacc.2009.07.029.

108. Neeland IJ, Turer AT, Ayers CR, Powell-Wiley TM, Vega GL, FarzanehFar R, et al. Dysfunctional adiposity and the risk of prediabetes and type 2 diabetes in obese adults. JAMA. 2012; 308(11):1150-1159.

109. Kannel WB, Hjortland M, Castelli WP. Role of diabetes in congestive heart failure: the Framingham study. Am J Cardiol. 1974; 34(1):2934.

110. Ingelsson E, Sundström J, Ärnlöv J, Zethelius B, Lind L. Insulin resistance and risk of congestive heart failure. JAMA. 2005; 294(3):334-341.

111. Lakka HM, Laaksonen DE, Lakka TA, Niskanen LK, Kumpusalo E, Tuomilehto J, et al. The metabolic syndrome and total and cardiovascular disease mortality in middle-aged men. JAMA. 2002; 288(21):2709-2716.

112. Boyer JK, Thanigaraj S, Schechtman KB, Pérez JE. Prevalence of ventricular diastolic dysfunction in asymptomatic, normotensive patients with diabetes mellitus. Am J Cardiol. 2004; 93(7):870-875.

113. De las Fuentes L, Brown AL, Mathews SJ, Waggoner AD, Soto PF, Gropler RJ, et al. Metabolic syndrome is associated with abnormal left ventricular diastolic function independent of LV mass. Eur Heart J. 2007; 28(5):553-559.

114. Dinh W, Lankisch M, Nickl W, Scheyer D, Scheffold T, Kramer F, et al. Insulin resistance and glycemic abnormalities are associated with deterioration of left ventricular diastolic function: a cross-sectional study. Cardiovasc Diabet. 2010; 9:63-76. doi: 10.1186/1475-28409-63.

115. Russo C, Jin Z, Homma S, Rundek T, Elkind MS, Sacco RL, et al. Effect of obesity and overweight on left ventricular diastolic function. A community-based study in an elderly cohort. J Am Coll Cardiol. 2011; 57(12):1368-1374. doi: 10.1016/j.jacc.2010.10.042.

116. Abel ED, Litwin ES, Sweeney G. Cardiac remodelling in obesity. Physiol Rev. 2008; 88(2):389-419. doi: 10.1152/physrev.00017.2007.

117. Falcao-Pires I, Leite-Moreira AF. Diabetic cardiomyopathy: understanding the molecular and cellular basis to progress in diagnosis and treatment. Heart Fail Rev. 2012; 17(3):325-344. doi: 10.1007/s10741-011-9257-z.

118. Witteles RM, Fowler MB. Insulin-resistant cardiomyopathy. J Am Coll Cardiol. 2008; 51(2):93-102. doi: 10.1016/j.jacc.2007.10.021.

119. Asbun J, Villareal FJ. The pathogenesis of myocardial fibrosis in the setting of diabetic cardiomyopathy. J Am Coll Cardiol. 2006; 47(4):693-700

120. Goldin A, Beckman JA, Schmidt AM, Creager MA. Advanced glycation end products: sparking the development of diabetic vascular injury. Circulation. 2006; 114(6):597-605.

121. Turkbey EB, McClelland RL, Kronmal RA, Burke GL, Bild DE, Tracy $\mathrm{RP}$, et al. The impact of obesity on the left ventricle: the Multi-Ethnic Study of Atherosclerosis (MESA). JACC Cardiovasc Imaging. 2010; 3(3):266-274. doi: 10.1016/j.jcmg.2009.10.012.

122. Diamant M, Lamb HJ, Groeneveld Y, Endert EL, Smit JW, Bax JJ, et al. Diastolic dysfunction is associated with altered myocardial metabolism in asymptomatic normotensive patients with wellcontrolled type 2 diabetes mellitus. J Am Coll Cardiol. 2003; 42(2):328-335.

123. Rider OJ, Francis JM, Ali MK, Holloway C, Pegg T, Robson MD, et al. Effects of catecholamine stress on diastolic function and myocardial energetics in obesity. Circulation. 2012; 125(12):1511-1519. doi: 10.1161/CIRCULATIONAHA.111.069518.

124. Ren J, Pulakat L, Whaley-Connell A, Sowers JR. Mitochondrial biogenesis in the metabolic syndrome and cardiovascular disease. ] Mol Med(Berl). 2010; 88(10):993-1001. doi: 10.1007/s00109-0100663-9.

125. Boudina S, Abel ED. Diabetic cardiomyopathy revisited. Circulation. 2007; 115(25):3213-3223.

126. van Heerebeek L, Hamdani N, Handoko ML, Falcao-Pires I, Musters RJ, Kupreishvili K, et al. Diastolic stiffness of the failing diabetic heart: Importance of fibrosis, advanced glycation endproducts, and myocyte resting tension. Circulation. 2008; 117(1):43-51.

127. Liu S, MaX, Gong M, Shi L, Lincoln T, Wang S. Glucose down-regulation of cGMP-dependent protein kinase I expression in vascular smooth muscle cells involves $\mathrm{NAD}(\mathrm{P}) \mathrm{H}$ oxidase-derived reactive oxygen species. Free Radic Biol Med. 2007; 42(6):852-863.

128. Rizzo NO, Maloney E, Pham M, Luttrell I, Wessells H, Tateya $\mathrm{S}$, et al. Reduced NO-cGMP signaling contributes to vascular inflammation and insulin resistance induced by high-fat feeding. Arterioscler Thromb Vasc Biol. 2010; 30(4):758-765. doi: 10.1161/ ATVBAHA.109.199893.

129. Roger VL, Go AS, Lloyd-Jones DM, Benjamin EJ, Berry JD, Borden WB, et al; American Heart Association Statistics Committee and Stroke Statistics Subcommittee. Executive summary: heart disease and stroke statistics--2012 update: a report from the American Heart Association. Circulation. 2012; 125(1):188-197. doi: 10.1161/ CIR.0b013e3182456d46.

130. Prospective Studies Collaboration, Whitlock G, Lewington S, Sherliker P, Clarke R, Emberson J, et al. Body-mass index and causespecific mortality in 900000 adults: collaborative analyses of 57 prospective studies. Lancet. 2009; 373(9669):1083-1096. doi: 10.1016/S0140-6736(09)60318-4.

131. Murphy NF, MacIntyre K, Stewart S, Hart CL, Hole D, McMurray JJ. Long-term cardiovascular consequences of obesity: 20-year followup of more than 15000 middle-aged men and women (the RenfrewPaisley study). Eur Heart J. 2006; 27(1):96-106. 
132. Fox CS, Pencina MJ, Meigs JB, Vasan RS, Levitzky YS, D’Agostino RB Sr. Trends in the incidence of type 2 diabetes mellitus from the 1970s to the 1990s: the Framingham Heart Study. Circulation. 2006; 113(25):2914-2918.

133. Haass M, Kitzman DW, Anand IS, Miller A, Zile MR, Massie BM, et al. Body mass index and adverse cardiovascular outcomes in heart failure patients with preserved ejection fraction: results from the Irbesartan in Heart Failure with Preserved Ejection Fraction (I-PRESERVE) trial. Circ Heart Fail. 2012; 4(3):324-331. doi: 10.1161/CIRCHEARTFAILURE.110.959890.

134. Kardassis D, Bech-Hanssen O, Schönander M, Sjöström L, Karason K The influence of body composition, fat distribution, and sustained weight loss on left ventricular mass and geometry in obesity. Obesity(Silver Spring). 2012; 20(3):605-611. doi: 10.1038/ oby.2011.101.

135. Wong C, Marwick TH. Obesity cardiomyopathy: pathogenesis and pathophysiology. Nat Clin Pract Cardiovasc Med. 2007; 4(8):436443.

136. Martin JW, Briesmiester K, Bargardi A, Muzik O, Mosca L, Duvernoy CS. Weight changes and obesity predict impaired resting and endothelium-dependent myocardial blood flow in postmenopausal women. Clin Cardiol. 2005; 28(1):13-18.

137. Schindler TH, Cardenas J, Prior JO, Facta AD, Kreissl MC, Zhang XL, et al. Relationship between increasing body weight, insulin resistance, inflammation, adipocytokine leptin, and coronary circulatory function. J Am Coll Cardiol. 2006; 47(6):1188-1195.

138. Bagi Z, Feher A, Cassuto J. Microvascular responsiveness in obesity: implications for therapeutic intervention. Br J Pharmacol. 2012; 165(3):544-560. doi: 10.1111/j.1476-5381.2011.01606.x.

139. Prieto D, Contreras C, Sanchez A. Endothelial dysfunction, obesity and insulin resistance. Curr Vasc Pharmacol. 2014; 12(3):412-426.

140. Russo I, Del Mese P, Doronzo G, Mattiello L, Viretto M, Bosia A, et al. Resistance to the nitric oxide/cyclic guanosine 5' monophosphate/ protein kinase $G$ pathway in vascular smooth muscle cells from the obese zucker rat, a classical animal model of insulin resistance: role of oxidative stress. Endocrinology. 2008; 149(4):1480-1489.

141. Shoelson SE, Lee J, Goldfine AB. Inflammation and insulin resistance. J Clin Invest. 2006; 116(7):1793-1801.

142. Kim J, Montagnani M, Kon Koh K, Quon MJ. Reciprocal relationships between insulin resistance and endothelial dysfunction: molecular and pathophysiological pathways. Circulation. 2006; 113(15):18881904.

143. Salmenniemi U, Ruotsalainen E, Pihlajamäki J, Vauhkonen I, Kainulainen S, Punnonen K, et al. Multiple abnormalities in glucose and energy metabolism and coordinated changes in levels of adiponectin, cytokines, and adhesion molecules in subjects with metabolic syndrome. Circulation. 2004; 110(25):3842-3848.

144. Chen H, Montagnani M, Funahashi T, Shimomura I, Quon MJ. Adiponectin stimulates production of nitric oxide in vascular endothelial cells. J Biol Chem. 2003; 278(45):45021-45026.

145. Ouchi N, Kihara S, Arita Y, Okamoto Y, Maeda K, Kuriyama H, et al. Adiponectin, an adipocyte-derived plasma protein, inhibits endothelial NF-kappaB signaling through a cAMP-dependent pathway. Circulation. 2000; 102(11):1296-1301.

146. Reaven GM. Insulin resistance: the link between obesity and cardiovascular disease. Med Clin North Am. 2011; 95(5):875-892. doi: 10.1016/j.mcna.2011.06.002.
147. Turer AT, Hill JA, Elmquist JK, Scherer PE. Adipose tissue biology and cardiomyopathy: translational implications. Circ Res. 2012; 111(12):1565-1577. doi: 10.1161/CIRCRESAHA.111.262493.

148. Kosmala W, Jedrzejuk D, Derzhko R, Przewlocka-Kosmala M, Mysiak A, Bednarek-Tupikowska G. Left ventricular function impairment in patients with normal-weight obesity: contribution of abdominal fat deposition, profibrotic state, reduced insulin sensitivity, and proinflammatory activation. Circ Cardiovasc Imaging. 2012; 5(3):349-356. doi: 10.1161/CIRCIMAGING.111.969956.

149. El Assar M, Ruiz de Adana JC, Angulo J, Pindado Martínez ML, Hernández Matías A, Rodríguez-Mañas L. Preserved endothelial function in human obesity in the absence of insulin resistance. J Transl Med. 2013; 11:263. doi: 10.1186/1479-5876-11-263.

150. Wild S, Roglic G, Green A, Sicree R, King H. Global prevalence of diabetes. Estimates for the year 2000 and projections for 2030 Diabetes care. 2004; 27(5):1047-1053.

151. Raev DC. Which left ventricular function is impaired earlier in the evolution of diabetic cardiomyopathy? An echocardiographic study of young type I diabetic patients. Diabetes Care. 1994; 17(7):633639.

152. Jay D, Hitomi H, Griendling KK. Oxidative stress and diabetic cardiovascular complications. Free Radic Biol Med. 2006; 40(2):183192.

153. van Tol BA, Huijsmans RJ, Kroon DW, Schothorst M, Kwakkel G. Effects of exercise training on cardiac performance, exercise capacity and quality of life in patients with heart failure: a meta-analysis. Eur J Heart Fail. 2006; 8(8):841-850.

154. Piepoli MF, Davos C, Francis DP, Coats AJ; ExTraMATCH Collaborative. Exercise training meta-analysis of trials in patients with chronic heart failure (ExTraMATCH). BMJ. 2004; 328(7433):189.

155. Flynn KE, Piña IL, Whellan DJ, Lin L, Blumenthal JA, Ellis SJ, et al; HFACTION Investigators. Effects of exercise training on health status in patients with chronic heart failure: HF-ACTION randomized controlled trial. JAMA. 2009; 301(14):1451-1459. doi: 10.1001/ jama.2009.457.

156. Adamopoulos S, Parissis J, Kroupis C, Georgiadis M, Karatzas D, Karavolias G, et al. Physical training reduces peripheral markers of inflammation in patients with chronic heart failure. Eur Heart J. 2001; 22(9):791-797.

157. Boulé NG, Haddad E, Kenny GP, Wells GA, Sigal RJ. Effects of exercise on glycemic control and body mass in type 2 diabetes mellitus: a meta-analysis of controlled clinical trials. JAMA. 2001; 286(10):1218-1227.

158. Linke A, Schoene N, Gielen S, Hofer J, Erbs S, Schuler G, et al. Endothelial dysfunction in patients with chronic heart failure: systemic effects of lower-limb exercise training. J Am Coll Cardiol. 2001; 37(2):392-397.

159. Fujimoto N, Prasad A, Hastings JL, Arbab-Zadeh A, Bhella PS, Shibata $S$, et al. Cardiovascular effects of 1 year of progressive and vigorous exercise training in previously sedentary individuals older than 65 years of age. Circulation. 2010; 122(18):1797-1805. doi: 10.1161/ CIRCULATIONAHA.110.973784.

160. Kitzman DW, Brubaker PH, Herrington DM, Morgan TM, Stewart $\mathrm{KP}$, Hundley WG, et al. Effect of endurance exercise training on endothelial function and arterial stiffness in older patients with heart failure and preserved ejection fraction: a randomized, controlled, single-blind trial. J Am Coll Cardiol. 2013; 62 (7):584-592. doi: 10.1016/j.jacc.2013.04.033. 
161. Smart NA, Haluska B, Jeffriess L, Leung D. Exercise training in heart failure with preserved systolic function: a randomized controlled trial of the effects on cardiac function and functional capacity. Congest Heart Fail. 2012; 18(6):295-301. doi: 10.1111/j.17517133.2012.00295.x.

162. Sjöström L, Lindroos AK, Peltonen M, Torgerson J, Bouchard C Carlsson B, et al; Swedish Obese Subjects Study Scientific Group. Lifestyle, diabetes, and cardiovascular risk factors 10 years after bariatric surgery. N Engl J Med. 2004; 351(26):2683-2693.

163. Leichman JG, Wilson EB, Scarborough T, Aguilar D, Miller CC 3rd, Yu $S$, et al. Dramatic reversal of derangements in muscle metabolism and left ventricular function after bariatric surgery. Am J Med. 2008; 121(11):966-973. doi: 10.1016/j.amjmed.2008.06.033.

164. Wong CY, Byrne NM, O’Moore-Sullivan T, Hills AP, Prins JB, Marwick TH. Effect of weight loss due to lifestyle intervention on subclinical cardiovascular dysfunction in obesity (body mass index $>30 \mathrm{~kg} / \mathrm{m}^{2}$ ). Am J Cardiol. 2006; 98(12):1593-1598.

165. de las Fuentes L, Waggoner AD, Mohammed BS, Stein RI, Miller BV 3rd, Foster GD, et al. Effect of moderate diet-induced weight loss and weight regain on cardiovascular structure and function. J Am Coll Cardiol. 2009; 54(25):2376-2381. doi: 10.1016/j.jacc.2009.07.054.

166. Hammer S, Snel M, Lamb HJ, Jazet IM, van der Meer RW, Pijl H, et al. Prolonged caloric restriction in obese patients with type 2 diabetes mellitus decreases myocardial triglyceride content and improves myocardial function. J Am Coll Cardiol. 2008; 52(12):1006-1012. doi: 10.1016/j.jacc.2008.04.068.

167. Kaltman AJ, Goldring RM. Role of circulatory congestion in the cardiorespiratory failure of obesity. Am J Med. 1976; 60(5):645-653.

168. Heilbronn LK, Noakes M, Clifton PM. Energy restriction and weight loss on very-low-fat diets reduce C-reactive protein concentrations in obese, healthy women. Arterioscler Thromb Vasc Biol. 2001; 21(6):968-970.

169. Ziccardi P, Nappo F, Giugliano G, Esposito K, Marfella R, Cioffi M, et al. Reduction of inflammatory cytokine concentrations and improvement of endothelial functions in obese women after weight loss over one year. Circulation. 2002; 105(7):804-809.

170. Romero-Corral A, Sert-Kuniyoshi FH, Sierra-Johnson J, Orban M, Gami A, Davison D, et al. Modest visceral fat gain causes endothelial dysfunction in healthy humans. J Am Coll Cardiol. 2010; 56(8):662666. doi: $10.1016 / \mathrm{j} . j \mathrm{acc} .2010 .03 .063$

171. Ikonomidis I, Mazarakis A, Papadopoulos C, Patsouras N, Kalfarentzos F, Lekakis J, et al. Weight loss after bariatric surgery improves aortic elastic properties and left ventricular function in individuals with morbid obesity: a 3-year follow-up study. J Hypertens. 2007; 25(2):439-447.

172. Garza CA, Pellikka PA, Somers VK, Sarr MG, Collazo-Clavell ML Korenfeld $Y$, et al. Structural and functional changes in left and right ventricles after major weight loss following bariatric surgery for morbid obesity. Am J Cardiol. 2010; 105(4):550-556. doi: 10.1016/j. amjcard.2009.09.057.

173. Hotta K, Funahashi T, Arita Y, Takahashi M, Matsuda M, Okamoto $\mathrm{Y}$, et al. Plasma concentrations of a novel, adipose-specific protein, adiponectin, in type 2 diabetic patients. Arterioscler Thromb Vasc Biol. 2000; 20(6):1595-1599.

174. Esposito K, Marfella R, Ciotola M, Di Palo C, Giugliano F, Giugliano G, et al. Effect of a mediterranean-style diet on endothelial dysfunction and markers of vascular inflammation in the metabolic syndrome: a randomized trial. JAMA. 2004; 292(12):1440-1446.
175. Esposito K, Giugliano F, Di Palo C, Giugliano G, Marfella R, D’Andrea $\mathrm{F}$, et al. Effect of lifestyle changes on erectile dysfunction in obese men: a randomized controlled trial. JAMA. 2004; 291(24):29782984.

176. Wegge JK, Roberts CK, Ngo TH, Barnard RJ. Effect of diet and exercise intervention on inflammatory and adhesion molecules in postmenopausal women on hormone replacement therapy and at risk for coronary artery disease. Metabolism. 2004; 53(3):377-381.

177. Lymperopoulos A, Rengo G, Koch WJ. Adrenergic nervous system in heart failure: pathophysiology and therapy. Circ Res. 2013; 113(6):739-753. doi: 10.1161/CIRCRESAHA.113.300308.

178. Triposkiadis F, Karayannis G, Giamouzis G, Skoularigis J, Louridas G, Butler J. The sympathetic nervous system in heart failure physiology, pathophysiology, and clinical implications. J Am Coll Cardiol. 2009; 54(19):1747-1762. doi: 10.1016/j.jacc.2009.05.015.

179. Maggioni AP. Efficacy of Angiotensin receptor blockers in cardiovascular disease. Cardiovasc Drugs Ther. 2006; 20(4):295308.

180. Schmieder RE. Mechanisms for the clinical benefits of angiotensin II receptor blockers. Am J Hypertens 2005; 18 (5 Pt 1):720-730.

181. Weber MA. The angiotensin II receptor blockers: opportunities across the spectrum of cardiovascular disease. Rev Cardiovasc Med. 2002; 3(4):183-191.

182. Guichard JL, Clark D 3rd, Calhoun DA, Ahmed MI. Aldosterone receptor antagonists: current perspectives and therapies. Vasc Health Risk Manag. 2013; 9:321-331. doi: 10.2147/VHRM.S33759.

183. Edelmann F, Wachter R, Schmidt AG, Kraigher-Krainer E, Colantonio C, Kamke W, et al; Aldo-DHF Investigators. Effect of spironolactone on diastolic function and exercise capacity in patients with heart failure with preserved ejection fraction: the Aldo-DHF randomized controlled trial. JAMA. 2013; 309(8):781-791. doi: 10.1001/ jama.2013.905.

184. Hamdani N, Paulus WJ, van Heerebeek L, Borbély A, Boontje NM, Zuidwijk MJ, et al. Distinct myocardial effects of beta-blocker therapy in heart failure with normal and reduced left ventricular ejection fraction. Eur Heart J. 2009; 30(15):1863-1872. doi: 10.1093/ eurheartj/ehp189.

185. Zhu WZ, Wang SQ, Chakir K, Yang D, Zhang T, Brown JH, et al. Linkage of beta1-adrenergic stimulation to apoptotic heart cell death through protein kinase A-independent activation of $\mathrm{Ca} 2+/$ calmodulin kinase II. J Clin Invest. 2003; 111(5):617-625.

186. Zhu WZ, Zheng M, Koch WJ, Lefkowitz RJ, Kobilka BK, Xiao RP. Dual modulation of cell survival and cell death by beta(2)-adrenergic signaling in adult mouse cardiac myocytes. Proc Natl Acad Sci U S A. 2001; 98(4):1607-1612.

187. Zaccolo M, Pozzan T. Discrete microdomains with high concentration of cAMP in stimulated rat neonatal cardiac myocytes. Science. 2002; 295(5560):1711-1715.

188. Zaccolo M. cAMP signal transduction in the heart: understanding spatial control for the development of novel therapeutic strategies. Br J Pharmacol. 2009; 158(1):50-60. doi: 10.1111/j.14765381.2009.00185.x.

189. Movsesian MA, Bristow MR. Alterations in cAMP-mediated signaling and their role in the pathophysiology of dilated cardiomyopathy. Curr Top Dev Biol. 2005; 68:25-48.

190. Lee DI, Kass DA. Phosphodiesterases and cyclic GMP regulation 
in heart muscle. Physiology (Bethesda). 2012; 27:248-258. doi: 10.1152/physiol.00011.2012.

191. Skeberdis VA, Gendviliene V, Zablockaite D, Treinys R, Macianskiene $\mathrm{R}$, Bogdelis A, et al. beta3-adrenergic receptor activation increases human atrial tissue contractility and stimulates the L-type Ca2+ current. J Clin Invest. 2008; 118(9):3219-3227. doi: 10.1172/ JCI32519.

192. Moniotte S, Kobzik L, Feron O, Trochu JN, Gauthier C, Balligand JL. Upregulation of beta(3)-adrenoceptors and altered contractile response to inotropic amines in human failing myocardium. Circulation. 2001; 103(12):1649-1655.

193. Liggett SB, Freedman NJ, Schwinn DA, Lefkowitz RJ. Structural basis for receptor subtype-specific regulation revealed by a chimeric beta 3/beta 2-adrenergic receptor. Proc Natl Acad Sci U S A. 1993; 90(8):3665-3669.

194. Lee DI, Vahebi S, Tocchetti CG, Barouch LA, Solaro RJ, Takimoto E, et al. PDE5A suppression of acute beta-adrenergic activation requires modulation of myocyte beta-3 signaling coupled to PKG-mediated troponin I phosphorylation. Basic Res Cardiol. 2010; 105(3):337347. doi: 10.1007/s00395-010-0084-5.

195. Mongillo M, Tocchetti CG, Terrin A, Lissandron V, Cheung YF Dostmann WR, et al. Compartmentalized phosphodiesterase-2 activity blunts beta-adrenergic cardiac inotropy via an NO/cGMPdependent pathway. Circ Res. 2006; 98(2):226-234.

196. Stangherlin A, Gesellchen F, Zoccarato A, Terrin A, Fields LA, Berrera $\mathrm{M}$, et al. cGMP signals modulate cAMP levels in a compartmentspecific manner to regulate catecholamine-dependent signaling in cardiac myocytes. Circ Res.2011; 108:929-939. doi: 10.1161/ CIRCRESAHA.110.230698.

197. Münzel T, Gori T. Nebivolol: the somewhat-different beta-adrenergic receptor blocker. J Am Coll Cardiol. 2009; 54(16):1491-1499. doi: 10.1016/j.jacc.2009.05.066.

198. Conraads VM, Metra M, Kamp O, De Keulenaer GW, Pieske B, Zamorano J, et al. Effects of the long-term administration of nebivolol on the clinical symptoms, exercise capacity, and left ventricular function of patients with diastolic dysfunction: results of the ELANDD study. Eur J Heart Fail. 2012; 14(2):219-225. doi: 10.1093/eurjhf/hfr161.

199. Paulus WJ, Vantrimpont PJ, Shah AM. Acute effects of nitric oxide on left ventricular relaxation and diastolic distensibility in humans. Assessment by bicoronary sodium nitroprusside infusion. Circulation. 1994; 89(5):2070-2078.

200. Trochu JN, Bouhour JB, Kaley G, Hintze TH. Role of endotheliumderived nitric oxide in the regulation of cardiac oxygen metabolism: implications in health and disease. Circ Res. 2000; 87(12):11081117.

201. McMurray JJ, Adamopoulos S, Anker SD, Auricchio A, Böhm M, Dickstein K, et al. ESC Guidelines for the diagnosis and treatment of acute and chronic heart failure 2012: The Task Force for the Diagnosis and Treatment of Acute and Chronic Heart Failure 2012 of the European Society of Cardiology. Developed in collaboration with the Heart Failure Association (HFA) of the ESC. Eur Heart J. 2012; 33(14):1787-1847. doi: 10.1093/eurheartj/ehs104.

202. Iachini Bellisarii F, Radico F, Muscente F, Horowitz J, De Caterina R. Nitrates and other nitric oxide donors in cardiology: current positioning and perspectives. Cardiovasc Drugs Ther. 2012; 26:5569. doi: 10.1007/s10557-011-6354-0.

203. Chirkov YY, Horowitz JD. Impaired tissue responsiveness to organic nitrates and nitric oxide: a new therapeutic frontier? Pharmacol Ther. 2007; 116(2):287-305.

204. Oelze M, Knorr M, Kröller-Schön S, Kossmann S, Gottschlich A, Rümmler R, et al. Chronic therapy with isosorbide-5-mononitrate causes endothelial dysfunction, oxidative stress, and a marked increase in vascular endothelin-1 expression. Eur Heart J. 2013; 34(41):3206-3216. doi: 10.1093/eurheartj/ehs100.

205. Cohn JN, Archibald DG, Ziesche S, Franciosa JA, Harston WE, Tristani $\mathrm{FE}$, et al. Effect of vasodilator therapy on mortality in chronic congestive heart failure. Results of a Veterans Administration Cooperative Study. N Engl J Med. 1986; 314(24):1547-1552.

206. Taylor AL, Ziesche S, Yancy C, Carson P, D’Agostino R Jr, Ferdinand $\mathrm{K}$, et al; African-American Heart Failure Trial Investigators. Combination of isosorbide dinitrate and hydralazine in blacks with heart failure. N Engl J Med. 2004; 351(20):2049-2057.

207. Münzel T, Kurz S, Rajagopalan S, Thoenes M, Berrington WR, Thompson JA, et al. Hydralazine prevents nitroglycerin tolerance by inhibiting activation of a membrane-bound NADH oxidase. A new action for an old drug. J Clin Invest. 1996; 98(6):1465-1470.

208. Kamath SA, Drazner MH, Wynne J, Fonarow GC, Yancy CW. Characteristics and outcomes in African American patients with decompensated heart failure. Arch Intern Med. 2008; 168(11):11521158. doi: 10.1001/archinte.168.11.1152.

209. Borlaug BA, Melenovsky V, Marhin T, Fitzgerald P, Kass DA. Sildenafil inhibits beta-adrenergic stimulated cardiac contractility in humans. Circulation. 2005; 112(17):2642-2649.

210. Takimoto E, Champion HC, Li M, Belardi D, Ren S, Rodriguez ER, et al. Chronic inhibition of cyclic GMP phosphodiesterase 5A prevents and reverses cardiac hypertrophy. Nat Med. 2005; 11(2):214-222.

211. Guazzi M, Vicenzi M, Arena R, Guazzi MD. PDE-5 inhibition with sildenafil improves left ventricular diastolic function, cardiac geometry and clinical status in patients with stable systolic heart failure: results of a 1-year prospective, randomized, placebo controlled trial. Circ Heart Fail. 2011; 4(1):8-17. doi: 10.1161/ CIRCHEARTFAILURE.110.944694.

212. Katz SD, Balidemaj K, Homma S, Wu H, Wang J, Maybaum S. Acute type 5 phosphodiesterase inhibition with sildenafil enhances flowmediated vasodilation in patients with chronic heart failure. J Am Coll Cardiol. 2000; 36(3):845-851.

213. Guazzi M, Vicenzi M, Arena R, Guazzi MD. Pulmonary hypertension in heart failure with preserved ejection fraction: a target of phosphodiesterase-5 inhibition in a 1-year study. Circulation. 2011; 124(2):164-174. doi: 10.1161/CIRCULATIONAHA.110.983866.

214. Lewis GD, Lachmann J, Camuso J, Lepore JJ, Shin J, Martinovic ME, et al. Sildenafil improves exercise hemodynamics and oxygen uptake in patients with systolic heart failure. Circulation. 2007; 115(1):59-66.

215. Redfield MM, Chen HH, Borlaug BA, Semigran MJ, Lee KL, Lewis G, et al; RELAX Trial. Effect of phosphodiesterase-5 inhibition on exercise capacity and clinical status in heart failure with preserved ejection fraction: a randomized clinical trial. JAMA. 2013; 309(12):12681277. doi: 10.1001/jama.2013.2024.

216. Greene SJ, Gheorghiade M, Borlaug BA, Pieske B, Vaduganathan M, Burnett JC Jr, et al. The cGMP signaling pathway as a therapeutic target in heart failure with preserved ejection fraction. J Am Heart Assoc. 2013; 2(6):e000536. doi: 10.1161/JAHA.113.000536.

217. Gheorghiade M, Marti CN, Sabbah HN, Roessig L, Greene SJ, Böhm $\mathrm{M}$, et al. Soluble guanylate cyclase: a potential therapeutic target for 
heart failure. Heart Fail Rev. 2013; 18(2):123-134. doi: 10.1007/ s10741-012-9323-1.

218. Schulz E, Jansen T, Wenzel P, Daiber A, Münzel T. Nitric oxide, tetrahydrobiopterin, oxidative stress and endothelial dysfunction in hypertension. Antiox Redox Signal. 2008; 10(6):1115-1126. doi: 10.1089/ars.2007.1989.

219. Münzel T, Gori T, Bruno RM, Taddei S. Is oxidative stress a therapeutic target in cardiovascular disease? Eur Heart J. 2010; 31(22):27412748. doi: 10.1093/eurheartj/ehq396.

220. Mitrovic V, Jovanovic A, Lehinant S. Soluble guanylate cyclase modulators in heart failure. Curr Heart Fail Rep. 2011; 8(1):38-44 doi: 10.1007/s11897-010-0045-1.

221. Stasch JP, Schmidt PM, Nedvetsky PI, Nedvetskaya TY, H S AK, Meurer S, et al. Targeting the heme-oxidized nitric oxide receptor for selective vasodilatation of diseased blood vessels. J Clin Invest. 2006; 116(9):2552-2561.

222. Lapp H, Mitrovic V, Franz N, Heuer H, Buerke M, Wolfertz J, et al. Cinaciguat (BAY 58-2667) improves cardiopulmonary hemodynamics in patients with acute decompensated heart failure. Circulation. 2009; 119(21):2781-2788. doi: 10.1161/ CIRCULATIONAHA.108.800292.

223. Erdmann E, Semigran MJ, Nieminen MS, Gheorghiade M, Agrawal $\mathrm{R}$, Mitrovic $\mathrm{V}$, et al. Cinaciguat, a soluble guanylate cyclase activator, unloads the heart but also causes hypotension in acute decompensated heart failure. Eur Heart J. 2013; 34(1):57-67. doi: 10.1093/eurheartj/ehs196.

224. Ghofrani HA, Galiè N, Grimminger F, Grünig E, Humbert M, Jing ZC, et al; PATENT-1 Study Group. Riociguat for the treatment of pulmonary arterial hypertension. N Engl J Med. 2013; 369(4):330340. doi: 10.1056/NEJMoa1209655.

225. Ghofrani HA, D'Armini AM, Grimminger F, Hoeper MM, Jansa P, Kim NH, et al; CHEST-1 Study Group. Riociguat for the treatment of chronic thromboembolic pulmonary hypertension. N Engl J Med. 2013; 369(4):319-329. doi: 10.1056/NEJMoa1209657.

226. Bonderman D, Ghio S, Felix SB, Ghofrani HA, Michelakis E, Mitrovic $\mathrm{V}$, et al; Left Ventricular Systolic Dysfunction Associated With Pulmonary Hypertension Riociguat Trial (LEPHT) Study Group. Riociguat for patients with pulmonary hypertension caused by systolic left ventricular dysfunction: a phase IIb double-blind, randomized, placebo-controlled, dose-ranging hemodynamic study. Circulation. 2013; 128(5):502-511. doi: 10.1161/ CIRCULATIONAHA.113.001458.

227. Gaasch WH, Zile MR. Left ventricular structural remodeling in health and disease: with special emphasis on volume, mass, and geometry. J Am Coll Cardiol. 2011; 58(17):1733-1740. doi: 10.1016/j. jacc.2011.07.022.

228. Anand IS, Rector TS, Cleland JG, Kuskowski M, McKelvie RS, Persson H, et al. Prognostic value of baseline plasma amino-terminal pro-brain natriuretic peptide and its interactions with irbesartan treatment effects in patients with heart failure and preserved ejection fraction: findings from the I-PRESERVE trial. Circ Heart Fail. 2011; 4(5):569577. doi: 10.1161/CIRCHEARTFAILURE.111.962654.

229. Solomon SD, Zile M, Pieske B, Voors A, Shah A, Kraigher-Krainer E, et al. The angiotensin receptor neprilysin inhibitor LCZ696 in heart failure with preserved ejection fraction: a phase 2 double-blind randomised controlled trial. Lancet. 2012; 380(9851):1387-1395. doi: 10.1016/S0140-6736(12)61227-6.

230. Mills RM, LeJemtel TH, Horton DP, Liang C, Lang R, Silver MA, et al. Sustained hemodynamic effects of an infusion of nesiritide (human b-type natriuretic peptide) in heart failure: a randomized, doubleblind, placebo-controlled clinical trial. Natrecor Study Group. J Am Coll Cardiol. 1999; 34(1):155-162.

231. Bishu K, Hamdani N, Mohammed SF, Krüger M, Ohtani T, Ogut O, et al. Sildenafil and BNP acutely phosphorylate titin and improve diastolic distensbility in vivo. Circulation. 2011; 124(25):2882 2891. doi: 10.1161/CIRCULATIONAHA.111.048520.

232. O'Connor CM, Starling RC, Hernandez AF, Armstrong PW, Dickstein $\mathrm{K}$, Hasselblad V, et al. Effect of nesiritide in patients with acute decompensated heart failure. N Engl J Med. 2011; 365(1):32-43. doi: 10.1056/NEJMoa1100171.

233. Antoniades C1, Bakogiannis C, Leeson P, Guzik TJ, Zhang MH, Tousoulis D, et al. Rapid, direct effects of statin treatment on arterial redox state and nitric oxide bioavailability in human atherosclerosis via tetrahydrobiopterin-mediated endothelial nitric oxide synthase coupling. Circulation. 2011; 124(3):335-345. doi: 10.1161/ CIRCULATIONAHA.110.985150.

234. Ramasubbu K, Estep J, White DL, Deswal A, Mann DL. Experimental and clinical basis for the use of statins in patients with ischemic and nonischemic cardiomyopathy. J Am Coll Cardiol. 2008; 51(4):415426. doi: 10.1016/j.jacc.2007.10.009.

235. Fukuta H, Sane DC, Brucks S, Little WC. Statin therapy may be associated with lower mortality in patients with diastolic heart failure: A preliminary report. Circulation, 2005; 112(3):357-363.

236. Gissi-HF Investigators, Tavazzi L, Maggioni AP, Marchioli R, Barlera S, Franzosi MG, et al. Effect of rosuvastatin in patients with chronic heart failure (the GISSI-HF trial): a randomised, double-blind, placebo controlled trial. Lancet. 2008; 372(9645):1231-1239. doi: 10.1016/S0140-6736(08)61240-4.

237. Teerlink JR, Cotter G, Davison BA, Felker GM, Filippatos G, Greenberg BH, et al; RELAXin in Acute Heart Failure (RELAX-AHF) Investigators. Serelaxin, recombinant human relaxin-2, for treatment of acute heart failure (RELAX-AHF): a randomised, placebo-controlled trial. Lancet. 2013; 381(9860):29-39. doi: 10.1016/S0140-6736(12)61855-8.

238. Metra M, Cotter G, Davison BA, Felker GM, Filippatos G, Greenberg $\mathrm{BH}$, et al; RELAX-AHF Investigators Effect of serelaxin on cardiac, renal, and hepatic biomarkers in the Relaxin in Acute Heart Failure (RELAX-AHF) development program: correlation with outcomes. J Am Coll Cardiol. 2013; 61(2):196-206. doi: 10.1016/j. jacc.2012.11.005.

239. Teichman SL, Unemori E, Teerlink JR, Cotter G, Metra M. Relaxin: review of biology and potential role in treating heart failure. Curr Heart Fail Rep. 2010; 7(2):75-82. doi: 10.1007/s11897-010-0010-z.

240. Filippatos G, Teerlink JR, Farmakis D, Cotter G, Davison BA, Felker $\mathrm{GM}$, et al. Serelaxin in acute heart failure patients with preserved left ventricular ejection fraction: results from the RELAX-AHF trial. Eur Heart J. 2014; 35(16):1041-1050. doi: 10.1093/eurheartj/eht497. 